\title{
Determining the best population-level alcohol consumption model and its impact on estimates of alcohol-attributable harms
}

Tara Kehoe ${ }^{1,2^{*}}$, Gerrit Gmel ${ }^{1}$, Kevin D Shield ${ }^{1,9}$, Gerhard Gmel ${ }^{1,4,5,6}$ and Jürgen Rehm ${ }^{1,3,7,8,9}$

\begin{abstract}
Background: The goals of our study are to determine the most appropriate model for alcohol consumption as an exposure for burden of disease, to analyze the effect of the chosen alcohol consumption distribution on the estimation of the alcohol Population- Attributable Fractions (PAFs), and to characterize the chosen alcohol consumption distribution by exploring if there is a global relationship within the distribution.

Methods: To identify the best model, the Log-Normal, Gamma, and Weibull prevalence distributions were examined using data from 41 surveys from Gender, Alcohol and Culture: An International Study (GENACIS) and from the European Comparative Alcohol Study. To assess the effect of these distributions on the estimated alcohol PAFs, we calculated the alcohol PAF for diabetes, breast cancer, and pancreatitis using the three above-named distributions and using the more traditional approach based on categories. The relationship between the mean and the standard deviation from the Gamma distribution was estimated using data from 851 datasets for 66 countries from GENACIS and from the STEPwise approach to Surveillance from the World Health Organization.

Results: The Log-Normal distribution provided a poor fit for the survey data, with Gamma and Weibull distributions providing better fits. Additionally, our analyses showed that there were no marked differences for the alcohol PAF estimates based on the Gamma or Weibull distributions compared to PAFs based on categorical alcohol consumption estimates. The standard deviation of the alcohol distribution was highly dependent on the mean, with a unit increase in alcohol consumption associated with a unit increase in the mean of 1.258 (95\% Cl: 1.223 to 1.293$)\left(R^{2}=0.9207\right)$ for women and $1.171(95 \% \mathrm{Cl}: 1.144$ to 1.197$)\left(R^{2}=0.9474\right)$ for men.

Conclusions: Although the Gamma distribution and the Weibull distribution provided similar results, the Gamma distribution is recommended to model alcohol consumption from population surveys due to its fit, flexibility, and the ease with which it can be modified. The results showed that a large degree of variance of the standard deviation of the alcohol consumption Gamma distribution was explained by the mean alcohol consumption, allowing for alcohol consumption to be modeled through a Gamma distribution using only average consumption.
\end{abstract}

Keywords: Alcohol consumption, Empirical distribution, Gamma distribution, Log-Normal distribution, Weibull distribution, Population-Attributable Fraction, Exposure distribution, Up-estimation, Per capita consumption, Mean, Standard deviation

\section{Introduction}

Alcohol consumption is a component cause [1] for over 200 International Classification of Diseases (ICD-10) three-digit codes $[2,3]$. In other words, a fraction, usually called the Population-Attributable Fraction (PAF) of the

\footnotetext{
* Correspondence: t.kehoe@utoronto.ca

${ }^{1}$ Centre for Addiction and Mental Health (CAMH), Toronto, Canada

Full list of author information is available at the end of the article
}

incidence of these diseases, would disappear if exposure to one of the causal components was eliminated [4-7] (in the case of alcohol, under the counterfactual scenario of every person being a lifetime abstainer). The proportion of the diseases caused by alcohol consumption in a component cause model for a population is determined by both the patterns and volume of alcohol consumption and by the relative risks associated with

\section{Biomed Central}


each exposure level $[3,8]$. For most major diseases where alcohol plays a role (for example, alcohol-attributable cancers, pancreatitis, and cirrhosis of the liver), the average volume of alcohol consumption alone was found to be an adequate predictor of the risk [3,8-10]; however, some diseases and injuries (for example, ischemic heart disease, unintentional injuries, and intentional injuries) were found to be also dependent on drinking patterns [11-14].

The calculation of an alcohol PAF involves a threestage process: 1) estimation of an exposure distribution of alcohol, 2) establishment of the relative risk function, and 3 ) the solving of the equation for the PAF [15]. Since the distribution of alcohol consumption on an international level has not been agreed upon, the common approach is to estimate the PAF using categorical measurements rather than modeling it in a more mathematically appropriate continuous manner [16,17]. The mathematical expression is as follows:(Formula 1)

$$
P A F=\frac{\sum_{i=1}^{k} P_{i}\left(R R_{i}-1\right)}{\sum_{i=1}^{k} P_{i}\left(R R_{i}-1\right)+1}
$$

where $i$ is the exposure category with baseline exposure or no exposure, $i=0, R R_{i}$ is the relative risk at exposure level $i$ compared to no consumption, and $P_{i}$ is the prevalence of the $j^{\text {th }}$ category of exposure.

When a continuous distribution for the volume of alcohol consumption is used, this calculation can be represented by the following formula:(Formula 2)

$$
P A F(x)=\frac{P_{a} R R_{a}+P_{e x} R R_{e x}+\int_{0}^{150} P(x) R R(x) d x-1}{P_{a} R R_{a}+P_{e x} R R_{e x}+\int_{0}^{150} P(x) R R(x) d x}
$$

where $P_{a}$ is the prevalence of lifetime abstainers, $R R_{a}$ is the relative risk of lifetime abstainers, $P_{e x}$ is the prevalence of former drinkers, $R R_{e x}$ is the relative risk of former drinkers, $x$ is the average volume of alcohol consumption per day, $P(x)$ is the prevalence of alcohol consumption, and $R R(x)$ is the relative risk of drinkers [15]. Although this is the most accurate way to calculate a PAF, it requires that the distribution of alcohol consumption be known. Previous attempts at modeling alcohol consumption using a Log-Normal distribution have been criticized for various reasons $[18,19]$; however, the Log-Normal distribution has provided adequate approximations for most applications [20,21]. Recently, more adaptable distributions such as the Gamma distribution have been favored over the Log-Normal distribution $[15,22]$, and it has been suggested that a mixing of distributions is needed to separately model the frequency of drinking and the quantity of alcohol consumed [23].

There are two main instruments to monitor alcohol exposure currently used by countries and international organizations: 1) general population surveys and 2) estimates of per capita consumption, where per capita consumption is an aggregate measure of recorded, unrecorded, and tourist per capita consumption of alcohol (derived from sales, production, and other economic statistics) $[9,24,25]$. These instruments, however, have limitations [26].

There are no available surveys for many countries, and in some cases where they do exist they do not allow for the accurate estimation of the volume of consumption, as these surveys only ask about the absence or presence of drinking [27]. Existing surveys often considerably underestimate real consumption levels [28-30] by typically covering only $30 \%$ to $60 \%$ of alcohol sales [26]. As a result, per capita consumption figures are considered to be a best estimate of overall volume of consumption in a country [31]; however, per capita consumption does not provide any disaggregated statistic and, thus, does not provide age- and gender-specific consumption estimates. Since in some instances the risk relationship between alcohol consumption and disease-specific mortality is dependent on gender as well as on age, alcohol exposure by gender and age is required to estimate the PAF and to calculate the alcohol-attributable burden of disease in a population [3].

The problems noted above with respect to surveys lead to an underestimated burden of disease attributable to alcohol consumption when PAFs are calculated from population data without adjustment. As a consequence, methods have been developed to triangulate both average alcohol consumption derived from population surveys and from per capita consumption information $[15,26]$. However, current PAF calculation methods are based on categorical estimates of consumption with alcohol consumption being corrected by multiplying the two top alcohol consumption categories by the inverse of the estimated undercoverage (per capita consumption/the estimated per capita consumption from the survey) [17]. For most categories of disease where there is an association with volume of alcohol consumption, the dose-response relationship is nonlinear and, thus, distribution estimates of alcohol consumption by age and gender are required for accurate estimates of alcohol PAFs [3].

Given the recent recognition of the need to strengthen and disseminate information about alcohol as outlined in the World Health Organization's strategy to reduce harmful consumption of alcohol [32], there is a need to find an appropriate model for exposure, prevalence, and 
distribution of alcohol consumption that can easily be modeled to make the fit more compatible with per capita consumption data and that also has properties that make it possible to estimate the exposure distribution for countries that lack survey data except for estimates of prevalence of abstention. Thus, the first aim of this study is to assess internationally if alcohol consistently follows one of the three well-known right-skewed distributions, Log-Normal, Gamma, or Weibull, and to determine if the chosen exposure distribution has a significant effect on the estimation of a PAF, using the PAFs for pancreatitis, diabetes, and breast cancer as examples. The second aim of this study is to investigate if a global relationship between parameters exists so that a distribution of alcohol consumption can be estimated based on mean alcohol consumption.

\section{Methods \\ Description of underlying surveys}

This study used data from Gender, Alcohol and Culture: An International Study (GENACIS), from the European Comparative Alcohol Study (ECAS), and from the STEPwise approach to Surveillance (STEPS). Survey data were collected for the average volume of consumption for Argentina, Australia (two surveys from Australia were used: Australia and Australia1), Austria, Belize, Brazil, Canada, Costa Rica, Czech Republic, Denmark, Finland, France, Germany, Hungary, Iceland, India, Ireland, Isle of Man, Israel, Italy, Japan, Kazakhstan, Mexico, Netherlands, Nicaragua, Nigeria, Norway, Peru, Spain, Sri Lanka, Sweden, Switzerland, Uganda, United Kingdom, Uruguay, and the United States of America from GENACIS (three surveys from the United States of America were used: USA1, USA2, and USA3; USA1 was a 2001 longitudinal study that surveyed women only, and USA 2 and USA3 were 1995-1996 and 2000 National Alcohol Surveys, respectively); for Finland, France, Germany, Italy, Sweden, and the United Kingdom from ECAS; and for Cameroon, Côte D' Ivoire, Dominica, Democratic Republic of the Congo, Eritrea, Kuwait, Mali, Mozambique, American Samoa, Barbados, Benin, Botswana, Cape Verde, Republic of the Congo, Cook Islands, Indonesia, Madagascar, St. Kitts and Nevis, Swaziland, Zambia, Fiji, Kiribati, Marshall Islands, Mongolia, Nauru, Solomon Islands, Tokelau, Tonga, Vanuatu, Micronesia, and Samoa from STEPS. (For information on sampling methodology and the questions used in GENACIS surveys see [33-35], ECAS see [30], and STEPS see [36]). For most of the GENACIS surveys and for the ECAS surveys alcohol consumption was measured by a beverage-specific usual quantity-frequency technique (i.e., asking separate questions on usual frequency of drinking, and then eliciting the usual quantity per drinking occasion), and in the remaining
GENACIS surveys alcohol consumption was measured by a global quantity-frequency measure. In the STEPS surveys alcohol consumption was measured in standard drinks consumed in the seven days preceding the survey.

All data from surveys were divided by sex and age into eight age groups; 15-24, 25-34, 35-44, 45-54, 55-64, 65$74,75-84$, and $85+$.

\section{Methods for fitting the distributions}

As alcohol consumption distributions have been shown to have a unimodal shape, $[19,37,38]$ we evaluated the fit of the Log-Normal, Gamma, and Weibull distributions (unimodal distributions commonly used to fit right-skewed empirical data) to determine the most appropriate distribution to model alcohol consumption from national survey data. The Log-Normal, Gamma, and Weibull probability densities are similar in shape, but have significantly different tail behaviors. In the past, alcohol consumption has been more commonly modeled by the Log-Normal distribution as it is used to model continuous random quantities that are rightskewed and is based on the normal distribution, making it easy to fit, test, and modify [20,21]. Although alcohol consumption is frequently modeled using the Log-Normal distribution, empirical distributions often deviate considerably from the Log-Normal model. In comparison, the Gamma and Weibull distributions have a scale parameter and a shape parameter, making them more adaptable since the scale parameter can stretch or compress the distribution.

The Log-Normal distribution is a function of the mean $(\mu)$ and standard deviation $(\sigma)$ parameters, and describes a random variable $\mathrm{x}$ where $\log (\mathrm{x})$ is normally distributed. The probability density function of the LogNormal distribution can be expressed as follows:

$$
f(x ; \mu, \sigma)=\frac{1}{x \sigma \sqrt{2 \pi}} \exp \left\{-\frac{(\log x-\mu)^{2}}{2 \sigma^{2}}\right\}
$$

where $\mathrm{x}>0$ and $-\infty<\mu<\infty, \sigma>0$ The Gamma distribution is characterized by a shape $(\kappa)$ and a scale parameter $(\theta)$, has a mean of $\kappa \theta$ and a standard deviation of $\sqrt{\kappa \theta^{2}}$. The probability density function of the Gamma distribution can be expressed as follows:

$$
f(x ; \kappa, \theta)=\frac{x^{\kappa-1}}{\theta^{\kappa} \Gamma(\kappa)} \exp \left\{-\frac{x}{\theta}\right\}
$$

where $\mathrm{x}>0, \kappa>0, \theta>0$ and $\Gamma(\kappa)=\int_{0}^{\infty} t^{\kappa-1} \exp \{-t\} d t$ Similar to the Gamma distribution, the Weibull distribution is commonly characterized by a shape $(\gamma)$ and a scale parameter $(\theta)$. The 
Weibull distribution has a mean of $\theta \Gamma\left(\frac{1}{\gamma}+1\right)$ and a standard deviation of $\theta \sqrt{\Gamma\left(\frac{2}{\gamma}+1\right)-\Gamma\left(\frac{1}{\gamma}+1\right)^{2}}$, where $\Gamma(x)=\int_{0}^{\infty} t^{x-1} \exp \{-t\} d t$ is the Gamma function evaluated at $x$. The probability density function of the Weibull distribution is expressed as follows:

$$
f(x ; \theta, \gamma)=\frac{\gamma}{\theta}\left(\frac{x}{\theta}\right)^{\gamma-1} \exp \left\{-\left(\frac{x}{\theta}\right)^{\gamma}\right\}
$$

where $\mathrm{x} \geq 0, \gamma>0, \theta>0$ Maximum likelihood estimation was used to fit all three distribution models to the drinking population data obtained from GENACIS and ECAS. All missing values were excluded from the fitted models. The Newton-Raphson algorithm was used to optimize the likelihood equations solving for the maximum likelihood estimates of the unknown parameters [39]. Data values of alcohol consumption over $300 \mathrm{~g} /$ day were truncated to $300 \mathrm{~g} /$ day. Numerical integration utilizing the trapezoidal rule was used to characterize each distribution.

\section{Method for deriving the alcohol PAF}

We performed a sensitivity analysis where the alcohol PAFs for pancreatitis, diabetes, and breast cancer were calculated using a continuous model (Log-Normal, Gamma, and Weibull) and using a categorical model in order to see if the chosen exposure distribution had an effect on the estimation of the alcohol PAF. All PAFs were calculated with zero alcohol consumption as the counterfactual scenario, similarly to the Comparative Risk Analysis for alcohol. This counterfactual scenario under certain circumstances of a light drinking average alcohol consumption without heavy drinking occasions may not reflect the theoretical minimum risk depending on the distribution of diseases and cause of death in a society. However, for this paper these considerations are not relevant. The relative risks of lifetime abstainers and former drinkers for pancreatitis, diabetes, and breast cancer were obtained from the meta-analysis [40-42].

In order to illustrate that the alcohol PAF estimates based on the Gamma distribution model deviated only slightly from the PAF derived from the categorical model, we calculated the difference between the PAFs calculated for both models.

\section{Methods for characterizing the gamma distributions}

The Gamma distribution can be characterized by a shape $(\kappa)$ and a scale parameter $(\theta)$, where the mean and the standard deviation of the Gamma distribution can be obtained directly from the parameter estimates as follows:

$$
\mu=\kappa \theta \quad \text { and } \quad \sigma=\sqrt{\kappa \theta^{2}}
$$

Since the mean of the Gamma distribution is equal to the mean of the empirical distribution, the mean of the Gamma distribution does not need to be estimated from the shape and scale parameters.

A maximum likelihood algorithm (see description above) was used to obtain the shape and scale parameters using the maximum likelihood function for the shape and scale parameters of the Gamma distribution:

$$
l(\kappa, \theta)=(\kappa-1) \sum_{i=1}^{N} \ln \left(x_{i}\right)-\sum_{i=1}^{N} \frac{x_{i}}{\theta}-N \cdot \kappa \cdot \ln (\theta)-N \cdot \ln (\Gamma(\kappa))
$$

\section{Regression analysis}

The maximum likelihood method was used to fit a Gamma model in order to summarize the alcohol consumption of 66 countries by gender and age (in total 851 datasets [422 for women; 429 for men]). After the data was fit by a Gamma model, the relationship between the Gamma mean and the Gamma standard deviation was examined using various general linear models. The performance of the general linear models was then assessed by how well the assumption of homoscedasticity was upheld and based on the distribution of the residuals.

All data analyses were performed in $\mathrm{R}$ version 2.13.0 [43].

\section{Results}

\section{Modeling alcohol consumption as a distribution}

The three distributions, Log-Normal, Gamma, and Weibull, were fit to 41 datasets; parameter estimates are outlined in Table 1 for women and in Table 2 for men. The mean and standard deviation estimates from the empirical data and the estimates from each fitted model are summarized in Table 3 for women and in Table 4 for men. When comparing the empirical mean to each distribution's mean, we observed that the mean estimates from the Weibull distribution were much closer to the empirical mean than were the Log-Normal distribution mean estimates, while the mean estimates from the Gamma distribution were equal to the empirical mean. When comparing the standard deviation estimates, the estimates from the Log-Normal distribution deviated furthest from the empirical data, while there was no statistically significant difference between the empirical standard deviation estimate and the standard deviation estimates from either of the Weibull or the Gamma distributions.

Three countries with diverse economic conditions and drinking patterns, namely Germany, Sri Lanka, and 
Table 1 Parameter estimates from Log-Normal, Gamma, and Weibull models for women from 43 datasets

\begin{tabular}{|c|c|c|c|c|c|c|}
\hline \multirow[b]{2}{*}{ Country } & \multicolumn{2}{|c|}{ Log-Normal model parameter estimates } & \multicolumn{2}{|c|}{ Gamma model parameter estimates } & \multicolumn{2}{|c|}{ Weibull model parameter estimates } \\
\hline & Mean & Standard deviation & Scale & Shape & Scale & Shape \\
\hline Argentina & 0.14 & 1.93 & 9.17 & 0.48 & 2.92 & 0.60 \\
\hline Australia & 0.57 & 1.88 & 11.75 & 0.51 & 4.33 & 0.64 \\
\hline Australia 1 & 0.47 & 1.57 & 8.57 & 0.56 & 3.55 & 0.67 \\
\hline Austria & 1.91 & 0.92 & 8.45 & 1.26 & 10.85 & 1.05 \\
\hline Belize & 0.64 & 1.51 & 13.44 & 0.50 & 4.17 & 0.62 \\
\hline Brazil & 1.09 & 2.10 & 36.30 & 0.41 & 8.18 & 0.54 \\
\hline Canada & 1.06 & 1.41 & 9.92 & 0.69 & 5.78 & 0.77 \\
\hline Costa Rica & -0.28 & 1.81 & 7.20 & 0.45 & 1.88 & 0.57 \\
\hline Czech Republic & 1.04 & 1.70 & 16.47 & 0.54 & 6.49 & 0.66 \\
\hline Denmark & 1.37 & 1.40 & 9.37 & 0.84 & 7.46 & 0.89 \\
\hline ECAS: Finland & 1.07 & 1.20 & 6.51 & 0.88 & 5.26 & 0.87 \\
\hline ECAS: France & 0.94 & 1.56 & 10.94 & 0.63 & 5.51 & 0.72 \\
\hline ECAS: Germany & 1.05 & 1.34 & 9.21 & 0.72 & 5.53 & 0.78 \\
\hline ECAS: Italy & 1.37 & 1.59 & 15.91 & 0.64 & 8.45 & 0.74 \\
\hline ECAS: Sweden & 0.90 & 1.17 & 4.23 & 1.02 & 4.30 & 0.99 \\
\hline ECAS: UK & 1.70 & 1.48 & 19.03 & 0.69 & 11.13 & 0.77 \\
\hline Finland & 0.47 & 1.67 & 7.08 & 0.61 & 3.47 & 0.72 \\
\hline France & 1.62 & 1.05 & 9.30 & 0.98 & 8.75 & 0.92 \\
\hline Germany & 1.30 & 1.47 & 12.42 & 0.70 & 7.43 & 0.78 \\
\hline Hungary & -0.82 & 1.89 & 4.36 & 0.44 & 1.11 & 0.58 \\
\hline Iceland & 0.82 & 1.31 & 5.78 & 0.81 & 4.23 & 0.84 \\
\hline India & 1.31 & 2.16 & 42.29 & 0.42 & 10.39 & 0.55 \\
\hline Ireland & 2.01 & 1.23 & 15.55 & 0.91 & 13.53 & 0.91 \\
\hline Isle of Man & 1.18 & 1.85 & 16.98 & 0.57 & 7.59 & 0.69 \\
\hline Israel & -0.05 & 1.98 & 12.55 & 0.40 & 2.52 & 0.54 \\
\hline Italy & 1.52 & 1.39 & 12.97 & 0.77 & 8.95 & 0.83 \\
\hline Japan & -0.15 & 2.18 & 14.32 & 0.37 & 2.53 & 0.50 \\
\hline Kazakhstan & -0.52 & 1.93 & 6.67 & 0.42 & 1.52 & 0.56 \\
\hline Mexico & -1.15 & 1.63 & 5.03 & 0.37 & 0.76 & 0.53 \\
\hline Netherlands & 1.44 & 1.11 & 8.33 & 0.94 & 7.43 & 0.91 \\
\hline Nicaragua & 0.91 & 1.49 & 26.83 & 0.43 & 5.54 & 0.57 \\
\hline Nigeria & 1.84 & 2.31 & 65.85 & 0.43 & 18.29 & 0.56 \\
\hline Norway & 0.61 & 1.58 & 7.07 & 0.66 & 3.85 & 0.75 \\
\hline Peru & 0.16 & 0.91 & 1.62 & 1.18 & 1.89 & 0.98 \\
\hline Spain & 1.07 & 1.78 & 13.31 & 0.61 & 6.58 & 0.72 \\
\hline Sri Lanka & -2.28 & 1.69 & 3.31 & 0.30 & 0.27 & 0.46 \\
\hline Sweden & 0.44 & 1.26 & 4.15 & 0.79 & 2.93 & 0.83 \\
\hline Switzerland & 1.39 & 1.25 & 8.07 & 0.93 & 7.21 & 0.93 \\
\hline Uganda & 0.98 & 2.09 & 34.50 & 0.40 & 7.39 & 0.53 \\
\hline Uruguay & 0.19 & 1.90 & 11.60 & 0.45 & 3.10 & 0.58 \\
\hline USA 1 & 0.18 & 1.96 & 12.42 & 0.43 & 3.16 & 0.56 \\
\hline USA 2 & 0.30 & 1.62 & 11.49 & 0.47 & 3.12 & 0.59 \\
\hline USA 3 & 0.23 & 1.67 & 9.85 & 0.48 & 2.94 & 0.61 \\
\hline
\end{tabular}

Uganda, were selected to display their density curves (Log-Normal, Gamma, and Weibull) superimposed on the population-based data histograms; see Figures 1, 2, $3,4,5$, and 6 for both women and men. We observed a common trend among men in Figures 2, 4, and 6: the
Log-Normal distribution tended to underestimate the number of men who drank $25 \mathrm{~g} /$ day to $50 \mathrm{~g} /$ day, whereas the Gamma and Weibull distributions accurately estimated alcohol consumption for these populations. A similar trend was observed with respect to 
Table 2 Parameter estimates from Log-Normal, Gamma, and Weibull models for men from 41 datasets

\begin{tabular}{|c|c|c|c|c|c|c|}
\hline \multirow[b]{2}{*}{ Country } & \multicolumn{2}{|c|}{ Log-Normal model parameter estimates } & \multicolumn{2}{|c|}{ Gamma model parameter estimates } & \multicolumn{2}{|c|}{ Weibull model parameter estimates } \\
\hline & Mean & Standard deviation & Scale & Shape & Scale & Shape \\
\hline$\overline{\text { Argentina }}$ & 1.84 & 1.68 & 25.33 & 0.64 & 13.62 & 0.75 \\
\hline Australia & 1.63 & 1.69 & 18.79 & 0.67 & 10.99 & 0.78 \\
\hline Austria & 2.85 & 0.96 & 19.72 & 1.33 & 27.52 & 1.13 \\
\hline Belize & 2.06 & 1.55 & 37.69 & 0.59 & 16.85 & 0.69 \\
\hline Brazil & 1.57 & 2.01 & 47.07 & 0.44 & 12.55 & 0.57 \\
\hline Canada & 1.96 & 1.42 & 21.64 & 0.74 & 14.04 & 0.81 \\
\hline Costa Rica & 1.13 & 1.87 & 23.50 & 0.49 & 7.71 & 0.61 \\
\hline Czech Republic & 2.58 & 1.55 & 38.84 & 0.75 & 26.59 & 0.83 \\
\hline Denmark & 2.28 & 1.24 & 18.05 & 0.98 & 17.33 & 0.96 \\
\hline ECAS: Finland & 2.22 & 1.18 & 16.68 & 0.99 & 16.13 & 0.95 \\
\hline ECAS: France & 2.18 & 1.48 & 26.19 & 0.75 & 17.56 & 0.82 \\
\hline ECAS: Germany & 1.92 & 1.33 & 16.43 & 0.84 & 12.84 & 0.87 \\
\hline ECAS: Italy & 2.22 & 1.40 & 20.68 & 0.87 & 17.43 & 0.92 \\
\hline ECAS: Sweden & 1.79 & 1.26 & 13.48 & 0.87 & 10.94 & 0.88 \\
\hline ECAS: UK & 2.85 & 1.30 & 38.19 & 0.88 & 31.78 & 0.90 \\
\hline Finland & 1.76 & 1.51 & 17.08 & 0.75 & 11.58 & 0.83 \\
\hline France & 2.44 & 1.25 & 25.29 & 0.88 & 21.08 & 0.90 \\
\hline Germany & 2.27 & 1.37 & 21.29 & 0.88 & 18.07 & 0.92 \\
\hline Hungary & 1.10 & 1.81 & 17.13 & 0.55 & 6.95 & 0.67 \\
\hline Iceland & 1.64 & 1.25 & 9.84 & 0.96 & 9.17 & 0.95 \\
\hline India & 2.24 & 1.95 & 69.20 & 0.49 & 23.75 & 0.62 \\
\hline Ireland & 3.04 & 1.18 & 38.57 & 0.98 & 36.94 & 0.95 \\
\hline Isle of Man & 2.22 & 1.78 & 39.38 & 0.63 & 20.51 & 0.74 \\
\hline Israel & 1.02 & 1.87 & 22.11 & 0.48 & 6.85 & 0.61 \\
\hline Italy & 2.44 & 1.30 & 21.80 & 0.96 & 20.92 & 0.99 \\
\hline Japan & 1.63 & 2.19 & 37.45 & 0.49 & 13.60 & 0.63 \\
\hline Kazakhstan & 1.87 & 1.76 & 36.80 & 0.55 & 14.69 & 0.67 \\
\hline Mexico & 1.34 & 1.90 & 33.23 & 0.46 & 9.68 & 0.59 \\
\hline Netherlands & 2.28 & 1.17 & 17.45 & 1.00 & 17.27 & 0.98 \\
\hline Nicaragua & 2.03 & 1.52 & 38.43 & 0.58 & 16.28 & 0.68 \\
\hline Nigeria & 2.47 & 1.78 & 55.90 & 0.60 & 26.97 & 0.71 \\
\hline Norway & 1.66 & 1.44 & 15.92 & 0.74 & 10.25 & 0.80 \\
\hline Peru & 1.13 & 1.17 & 8.89 & 0.76 & 5.60 & 0.79 \\
\hline Spain & 2.28 & 1.49 & 25.30 & 0.81 & 19.04 & 0.87 \\
\hline Sri Lanka & 1.30 & 2.18 & 57.93 & 0.37 & 10.71 & 0.51 \\
\hline Sweden & 1.12 & 1.32 & 8.20 & 0.79 & 5.83 & 0.83 \\
\hline Switzerland & 2.37 & 1.12 & 17.65 & 1.05 & 18.27 & 0.97 \\
\hline Uganda & 2.75 & 1.79 & 70.07 & 0.61 & 35.42 & 0.73 \\
\hline Uruguay & 1.69 & 1.84 & 34.78 & 0.52 & 12.88 & 0.64 \\
\hline USA 2 & 1.41 & 1.72 & 25.65 & 0.53 & 9.50 & 0.64 \\
\hline USA 3 & 1.32 & 1.80 & 28.58 & 0.49 & 9.04 & 0.61 \\
\hline
\end{tabular}

women from Germany and Uganda who drank between $10 \mathrm{~g} /$ day to $30 \mathrm{~g} /$ day and for Sri Lankan women who drank between $0.5 \mathrm{~g} /$ day to $2.0 \mathrm{~g} /$ day.

Alcohol PAF estimates modeled using the Log-Normal, Gamma, and Weibull distributions, together with the proportion estimates for lifetime abstainers and former drinkers, are listed in Table 5 for breast cancer (women), Tables 6 and 7 for diabetes (women and men, respectively), and Tables 8 and 9 for pancreatitis (women and men, respectively).

The alcohol PAF estimates that incorporated the Gamma and Weibull distributions are very similar and, for the most part, are within $1 \%$ of one another. Since the Log-Normal distribution is known to have a heavy tail, and this study includes data values for alcohol consumption up to $300 \mathrm{~g} /$ day, the alcohol PAF estimates 
Table 3 Mean and standard deviation estimates from the empirical data, Log-Normal model, Gamma model, and the Weibull model for alcohol consumption of women from $\mathbf{4 3}$ datasets

\begin{tabular}{|c|c|c|c|c|c|c|c|c|c|}
\hline \multirow[b]{2}{*}{ Country } & \multicolumn{3}{|c|}{ Empirical data } & \multicolumn{2}{|c|}{ Log-Normal model } & \multicolumn{2}{|r|}{ Gamma model } & \multicolumn{2}{|r|}{ Weibull model } \\
\hline & Count & Mean & Standard deviation & Mean & Standard deviation & Mean & Standard deviation & Mean & Standard deviation \\
\hline Argentina & 381 & 4.38 & 6.77 & 7.35 & 46.50 & 4.38 & 6.34 & 4.39 & 7.69 \\
\hline Australia & 1172 & 6.04 & 9.52 & 10.40 & 60.39 & 6.04 & 8.42 & 6.06 & 9.90 \\
\hline Australia 1 & 3002 & 4.84 & 7.81 & 5.47 & 17.86 & 4.84 & 6.44 & 4.69 & 7.22 \\
\hline Austria & 1916 & 10.62 & 13.26 & 10.36 & 11.94 & 10.62 & 9.47 & 10.66 & 10.20 \\
\hline Belize & 386 & 6.74 & 16.63 & 5.92 & 17.44 & 6.74 & 9.52 & 5.98 & 10.02 \\
\hline Brazil & 283 & 14.80 & 29.63 & 26.75 & 240.21 & 14.80 & 23.18 & 14.27 & 28.60 \\
\hline Canada & 5850 & 6.88 & 10.79 & 7.82 & 19.76 & 6.88 & 8.26 & 6.75 & 8.90 \\
\hline Costa Rica & 367 & 3.21 & 6.33 & 3.90 & 19.86 & 3.21 & 4.81 & 3.00 & 5.57 \\
\hline Czech Republic & 1023 & 8.97 & 15.12 & 12.08 & 50.02 & 8.97 & 12.16 & 8.74 & 13.71 \\
\hline Denmark & 1042 & 7.89 & 8.85 & 10.48 & 26.03 & 7.89 & 8.59 & 7.89 & 8.85 \\
\hline ECAS: Finland & 469 & 5.71 & 9.65 & 6.00 & 10.77 & 5.71 & 6.09 & 5.63 & 6.47 \\
\hline ECAS: France & 382 & 6.85 & 9.83 & 8.64 & 27.71 & 6.85 & 8.66 & 6.77 & 9.54 \\
\hline ECAS: Germany & 512 & 6.93 & 21.77 & 7.05 & 15.85 & 6.62 & 7.80 & 6.39 & 8.30 \\
\hline ECAS: Italy & 404 & 10.23 & 14.99 & 14.08 & 48.17 & 10.23 & 12.76 & 10.17 & 13.94 \\
\hline ECAS: Sweden & 433 & 4.32 & 4.58 & 4.87 & 8.35 & 4.32 & 4.28 & 4.32 & 4.36 \\
\hline ECAS: UK & 498 & 13.14 & 19.31 & 16.34 & 46.06 & 13.14 & 15.81 & 12.97 & 17.02 \\
\hline Finland & 882 & 4.35 & 7.83 & 6.45 & 25.27 & 4.35 & 5.55 & 4.28 & 6.07 \\
\hline France & 4206 & 9.14 & 11.79 & 8.78 & 12.42 & 9.14 & 9.22 & 9.08 & 9.83 \\
\hline Germany & 4164 & 8.72 & 12.97 & 10.88 & 30.24 & 8.72 & 10.41 & 8.60 & 11.17 \\
\hline Hungary & 883 & 1.92 & 5.31 & 2.62 & 15.31 & 1.92 & 2.90 & 1.75 & 3.22 \\
\hline Iceland & 1072 & 4.70 & 7.41 & 5.34 & 11.37 & 4.70 & 5.21 & 4.63 & 5.53 \\
\hline India & 85 & 17.67 & 26.94 & 38.01 & 388.74 & 17.67 & 27.33 & 17.88 & 35.44 \\
\hline Ireland & 378 & 14.20 & 17.69 & 16.05 & 30.35 & 14.20 & 14.86 & 14.14 & 15.54 \\
\hline Isle of Man & 469 & 9.67 & 13.20 & 17.91 & 97.33 & 9.67 & 12.81 & 9.77 & 14.57 \\
\hline Israel & 1938 & 4.98 & 12.52 & 6.70 & 46.91 & 4.98 & 7.91 & 4.46 & 9.04 \\
\hline Italy & 1219 & 9.93 & 11.72 & 11.91 & 28.76 & 9.93 & 11.35 & 9.90 & 12.01 \\
\hline Japan & 864 & 5.27 & 11.72 & 9.17 & 97.39 & 5.27 & 8.68 & 5.02 & 11.15 \\
\hline Kazakhstan & 401 & 2.80 & 7.91 & 3.78 & 23.87 & 2.80 & 4.32 & 2.50 & 4.78 \\
\hline Mexico & 1406 & 1.88 & 7.32 & 1.20 & 4.39 & 1.88 & 3.07 & 1.37 & 2.82 \\
\hline Netherlands & 1505 & 7.84 & 10.50 & 7.83 & 12.20 & 7.84 & 8.08 & 7.78 & 8.58 \\
\hline Nicaragua & 147 & 11.43 & 34.88 & 7.52 & 21.56 & 11.43 & 17.51 & 8.94 & 16.78 \\
\hline Nigeria & 200 & 28.45 & 41.91 & 91.55 & 1322.58 & 28.45 & 43.28 & 30.12 & 57.50 \\
\hline Norway & 1004 & 4.64 & 7.03 & 6.39 & 21.38 & 4.64 & 5.73 & 4.59 & 6.21 \\
\hline Peru & 620 & 1.91 & 3.07 & 1.78 & 2.03 & 1.91 & 1.76 & 1.90 & 1.95 \\
\hline Spain & 427 & 8.07 & 11.17 & 14.34 & 69.00 & 8.07 & 10.36 & 8.12 & 11.50 \\
\hline Sri Lanka & 38 & 1.00 & 2.93 & 0.42 & 1.70 & 1.00 & 1.82 & 0.64 & 1.63 \\
\hline Sweden & 2226 & 3.29 & 4.51 & 3.42 & 6.75 & 3.29 & 3.69 & 3.24 & 3.94 \\
\hline Switzerland & 5362 & 7.50 & 10.07 & 8.77 & 17.04 & 7.50 & 7.78 & 7.48 & 8.09 \\
\hline Uganda & 280 & 13.78 & 26.60 & 23.46 & 206.14 & 13.78 & 21.80 & 13.25 & 27.17 \\
\hline Uruguay & 375 & 5.17 & 12.02 & 7.35 & 43.87 & 5.17 & 7.75 & 4.91 & 9.05 \\
\hline USA 1 & 854 & 5.37 & 10.39 & 8.11 & 54.33 & 5.37 & 8.17 & 5.21 & 9.95 \\
\hline USA 2 & 1310 & 5.35 & 14.44 & 5.00 & 17.90 & 5.35 & 7.84 & 4.76 & 8.46 \\
\hline USA 3 & 2274 & 4.75 & 10.65 & 5.09 & 19.93 & 4.75 & 6.84 & 4.36 & 7.57 \\
\hline
\end{tabular}


Table 4 Mean and standard deviation estimates from the empirical data, Log-Normal model, Gamma model, and the Weibull model for alcohol consumption of men from 41 datasets

\begin{tabular}{|c|c|c|c|c|c|c|c|c|c|}
\hline \multirow[b]{2}{*}{ Country } & \multicolumn{3}{|c|}{ Empirical data } & \multicolumn{2}{|c|}{ Log-Normal model } & \multicolumn{2}{|r|}{ Gamma model } & \multicolumn{2}{|r|}{ Weibull model } \\
\hline & Count & Mean & Standard deviation & Mean & Standard deviation & Mean & Standard deviation & Mean & Standard deviation \\
\hline Argentina & 359 & 16.26 & 21.80 & 25.79 & 102.88 & 16.26 & 20.29 & 16.29 & 22.18 \\
\hline Australia & 882 & 12.63 & 15.09 & 21.31 & 86.21 & 12.63 & 15.40 & 12.73 & 16.58 \\
\hline Austria & 2697 & 26.23 & 26.25 & 27.23 & 33.35 & 26.23 & 22.75 & 26.35 & 23.43 \\
\hline Belize & 957 & 22.52 & 41.05 & 26.19 & 83.46 & 22.31 & 29.00 & 21.51 & 31.79 \\
\hline Brazil & 325 & 20.78 & 37.89 & 35.81 & 265.46 & 20.78 & 31.27 & 20.16 & 37.64 \\
\hline Canada & 4833 & 16.09 & 24.60 & 19.65 & 50.51 & 16.02 & 18.62 & 15.84 & 19.82 \\
\hline Costa Rica & 285 & 11.47 & 18.97 & 17.91 & 101.55 & 11.47 & 16.42 & 11.30 & 19.36 \\
\hline Czech Republic & 1121 & 29.19 & 32.98 & 43.56 & 137.44 & 29.19 & 33.67 & 29.27 & 35.28 \\
\hline Denmark & 865 & 17.68 & 21.18 & 21.03 & 39.93 & 17.68 & 17.87 & 17.66 & 18.42 \\
\hline ECAS: Finland & 462 & 16.53 & 21.56 & 18.48 & 32.09 & 16.53 & 16.60 & 16.49 & 17.32 \\
\hline ECAS: France & 415 & 19.75 & 28.51 & 26.44 & 74.41 & 19.66 & 22.69 & 19.55 & 23.98 \\
\hline ECAS: Germany & 328 & 13.81 & 19.83 & 16.65 & 36.89 & 13.81 & 15.06 & 13.73 & 15.76 \\
\hline ECAS: Italy & 434 & 18.06 & 19.09 & 24.71 & 61.39 & 18.06 & 19.33 & 18.08 & 19.57 \\
\hline ECAS: Sweden & 449 & 11.77 & 17.59 & 13.28 & 26.13 & 11.77 & 12.60 & 11.66 & 13.29 \\
\hline ECAS: UK & 361 & 34.95 & 54.61 & 40.33 & 85.07 & 33.62 & 35.83 & 33.48 & 37.34 \\
\hline Finland & 864 & 12.88 & 17.32 & 18.14 & 53.44 & 12.88 & 14.83 & 12.84 & 15.63 \\
\hline France & 4697 & 22.24 & 25.21 & 24.83 & 47.92 & 22.24 & 23.72 & 22.18 & 24.67 \\
\hline Germany & 3510 & 18.79 & 20.74 & 24.77 & 58.38 & 18.79 & 20.00 & 18.79 & 20.45 \\
\hline Hungary & 991 & 9.38 & 15.16 & 15.50 & 78.87 & 9.38 & 12.68 & 9.25 & 14.34 \\
\hline Iceland & 1013 & 9.42 & 11.04 & 11.18 & 21.62 & 9.42 & 9.63 & 9.40 & 9.94 \\
\hline India & 498 & 34.82 & 54.78 & 63.16 & 417.87 & 34.20 & 48.65 & 34.40 & 58.26 \\
\hline Ireland & 385 & 37.82 & 43.73 & 42.23 & 73.86 & 37.82 & 38.19 & 37.74 & 39.61 \\
\hline Isle of Man & 420 & 24.90 & 36.39 & 45.31 & 217.60 & 24.64 & 31.15 & 24.77 & 34.16 \\
\hline Israel & 2005 & 10.59 & 19.71 & 15.91 & 89.50 & 10.59 & 15.30 & 10.19 & 17.71 \\
\hline Italy & 1429 & 20.98 & 19.35 & 26.89 & 56.90 & 20.98 & 21.39 & 20.98 & 21.13 \\
\hline Japan & 1009 & 18.51 & 25.29 & 55.72 & 605.09 & 18.51 & 26.33 & 19.42 & 32.43 \\
\hline Kazakhstan & 401 & 20.55 & 40.31 & 30.49 & 139.45 & 20.27 & 27.31 & 19.50 & 30.13 \\
\hline Mexico & 1833 & 15.48 & 30.37 & 23.46 & 141.72 & 15.37 & 22.60 & 14.86 & 26.61 \\
\hline Netherlands & 1679 & 17.47 & 18.78 & 19.46 & 33.31 & 17.47 & 17.46 & 17.46 & 17.89 \\
\hline Nicaragua & 263 & 22.26 & 40.29 & 24.27 & 73.44 & 22.26 & 29.25 & 21.16 & 31.91 \\
\hline Nigeria & 439 & 33.63 & 45.76 & 58.17 & 279.62 & 33.38 & 43.19 & 33.66 & 48.39 \\
\hline Norway & 945 & 11.78 & 19.42 & 14.67 & 38.42 & 11.78 & 13.70 & 11.59 & 14.57 \\
\hline Peru & 425 & 6.76 & 15.68 & 6.10 & 10.43 & 6.76 & 7.75 & 6.42 & 8.24 \\
\hline Spain & 603 & 20.44 & 24.47 & 29.64 & 84.47 & 20.44 & 22.74 & 20.43 & 23.56 \\
\hline Sri Lanka & 323 & 21.87 & 43.99 & 39.56 & 426.76 & 21.65 & 35.42 & 20.87 & 45.74 \\
\hline Sweden & 2348 & 6.49 & 9.17 & 7.30 & 15.79 & 6.49 & 7.30 & 6.42 & 7.74 \\
\hline Switzerland & 5126 & 18.55 & 24.86 & 20.15 & 32.01 & 18.54 & 18.09 & 18.50 & 19.05 \\
\hline Uganda & 378 & 42.93 & 52.50 & 78.02 & 382.06 & 42.80 & 54.76 & 43.42 & 61.01 \\
\hline Uruguay & 305 & 18.32 & 34.55 & 29.22 & 154.64 & 18.16 & 25.14 & 17.75 & 28.56 \\
\hline USA 2 & 1499 & 13.51 & 24.00 & 17.81 & 75.66 & 13.51 & 18.62 & 13.12 & 21.16 \\
\hline USA 3 & 2300 & 14.18 & 32.43 & 19.12 & 95.29 & 13.93 & 19.95 & 13.20 & 22.54 \\
\hline
\end{tabular}

from the Log-Normal distribution tend to be much larger and unrealistic when compared to the estimates from the Gamma and Weibull distributions.
Overall, the PAF estimates from the categorical model, Gamma model, and Weibull model are relatively similar when the survey data are more compact, but for those 


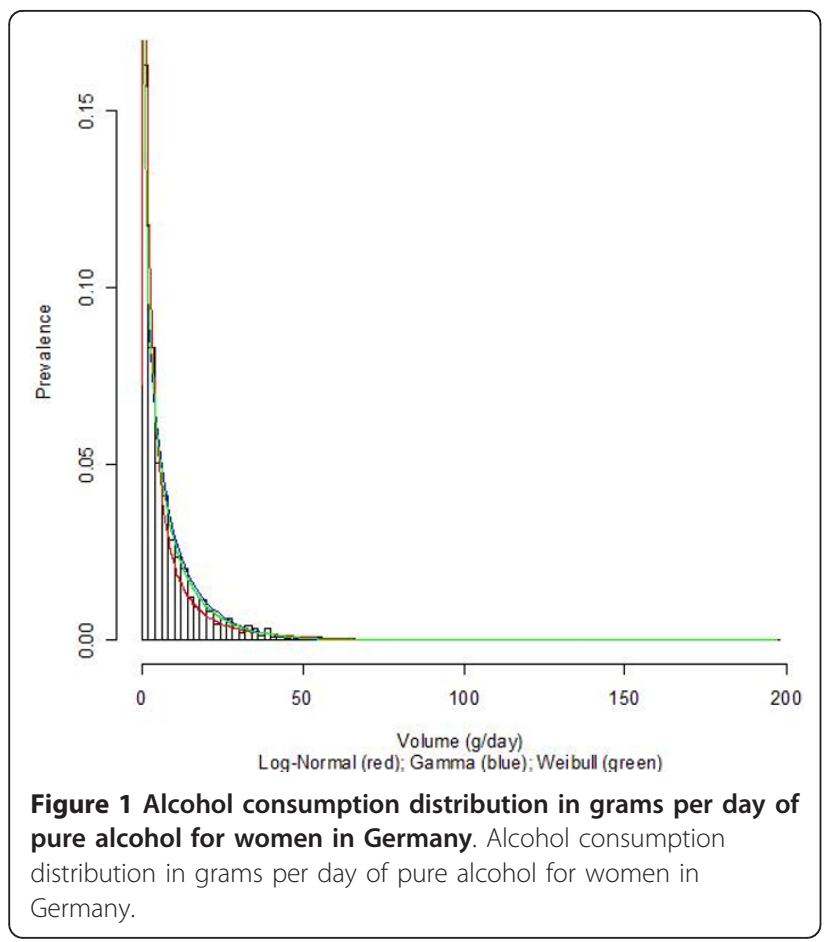

countries where data are more spread out, PAF estimates are more susceptible to sampling bias for diseases with a relatively linear or exponential risk relationship with alcohol, such as pancreatitis and breast cancer. For example, for Brazilian men the alcohol consumption prevalence data tend to be very spread out when compared to men from France, leading to a small difference

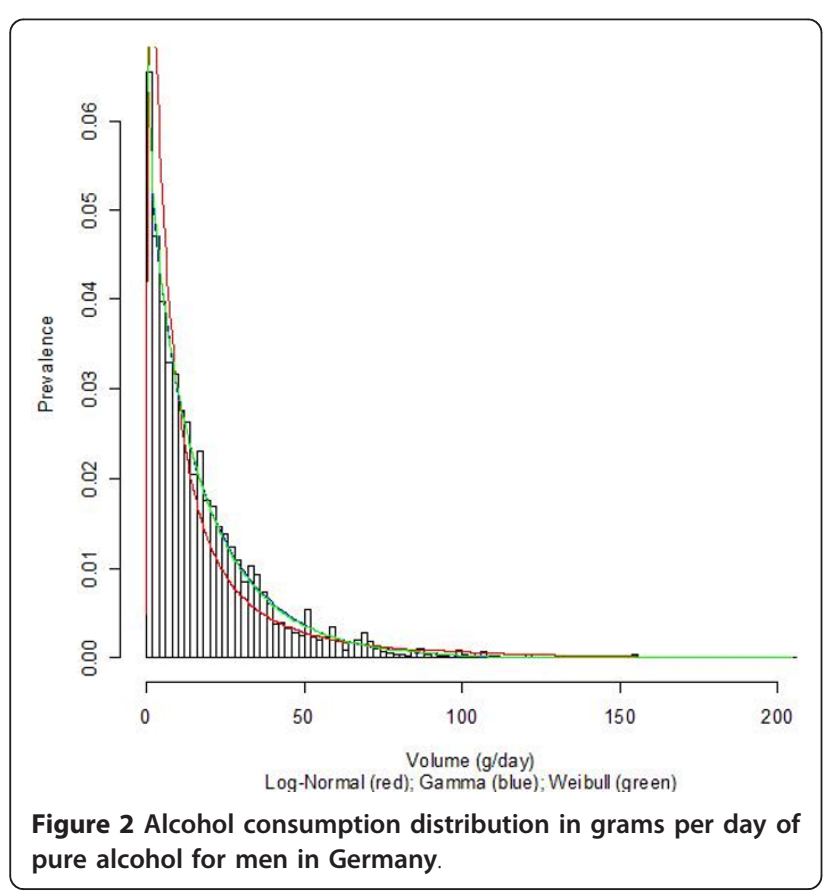

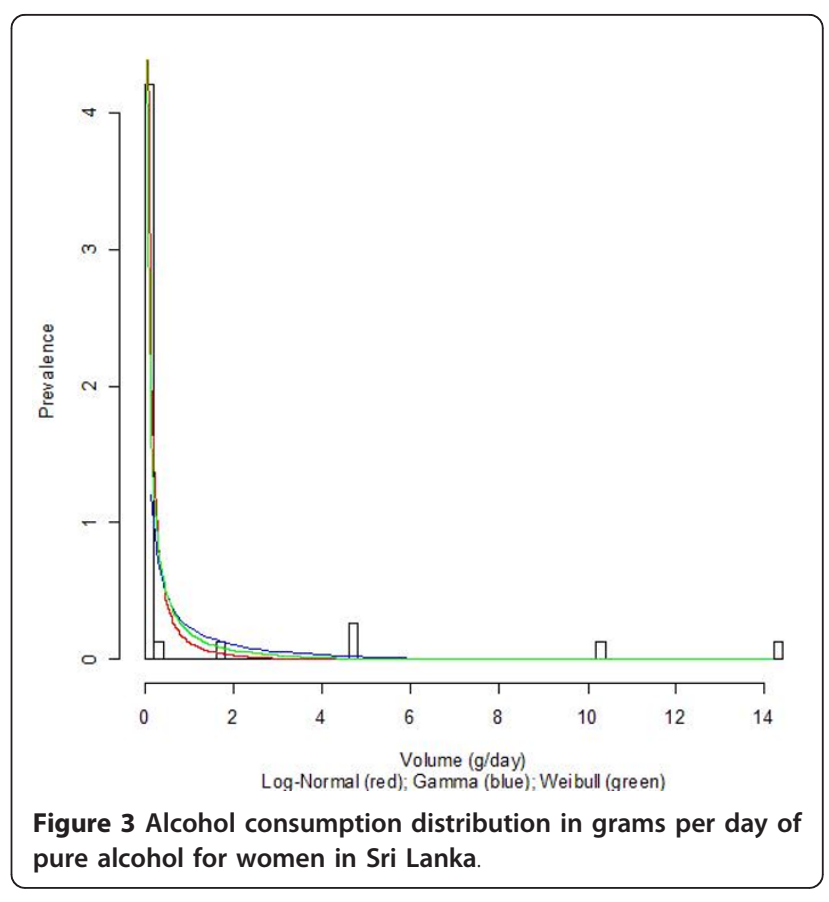

in the PAFs for pancreatitis. However, this trend does not apply when we look at a disease, such as diabetes, that has a J-shaped relative risk function. If we look at the same example, we find that the alcohol PAFs for diabetes provide similar estimates from the categorical model, Gamma model, Log-Normal model, and Weibull model for men from both Brazil and France. This is due to the fact that the relative risk functions are exponential

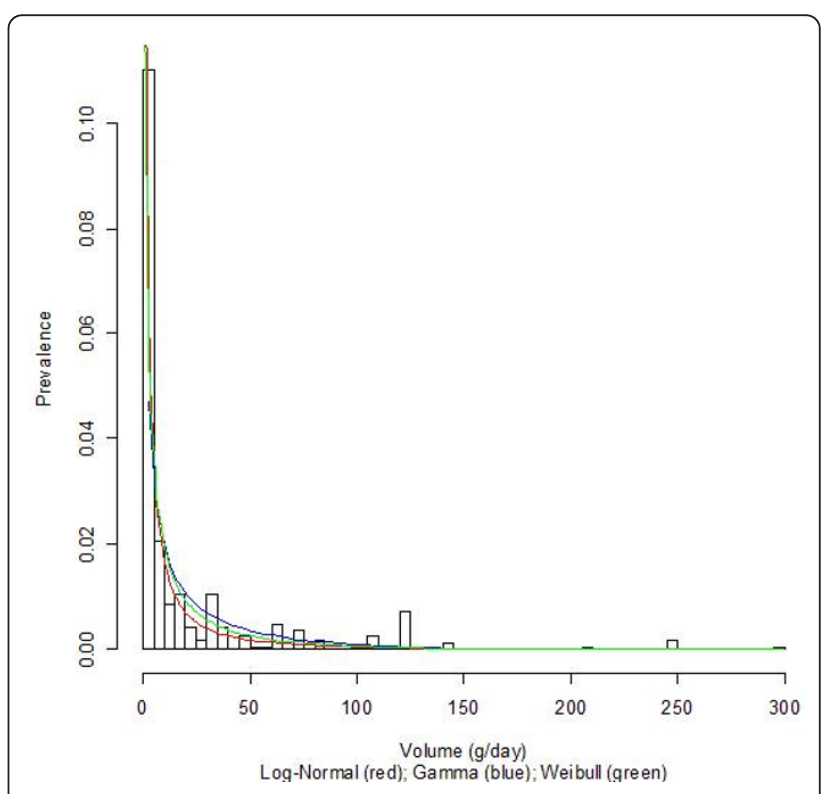

Figure 4 Alcohol consumption distribution in grams per day of pure alcohol for men in Sri Lanka. Alcohol consumption distribution in grams per day of pure alcohol for men in Sri Lanka. 


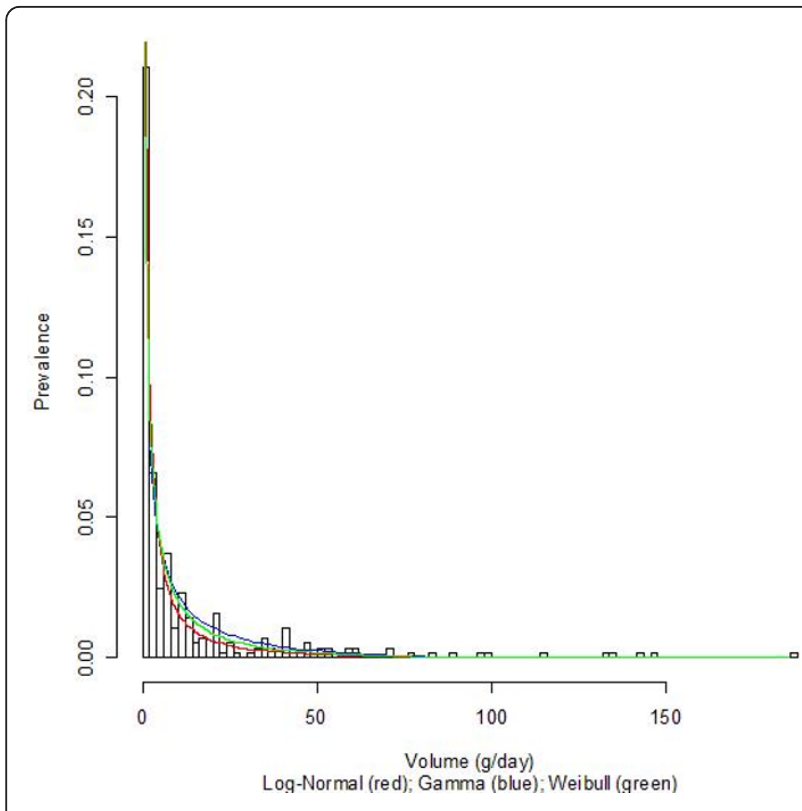

Figure 5 Alcohol consumption distribution in grams per day of pure alcohol for women in Uganda.

for pancreatitis and are J-shaped for diabetes and thus have different properties. The J-shaped curve in some cases leads to a negative PAF (which represents the fraction of deaths prevented) as the risk of diabetes at the population level is less under current levels of alcohol consumption than under the counterfactual scenario of no alcohol consumption.

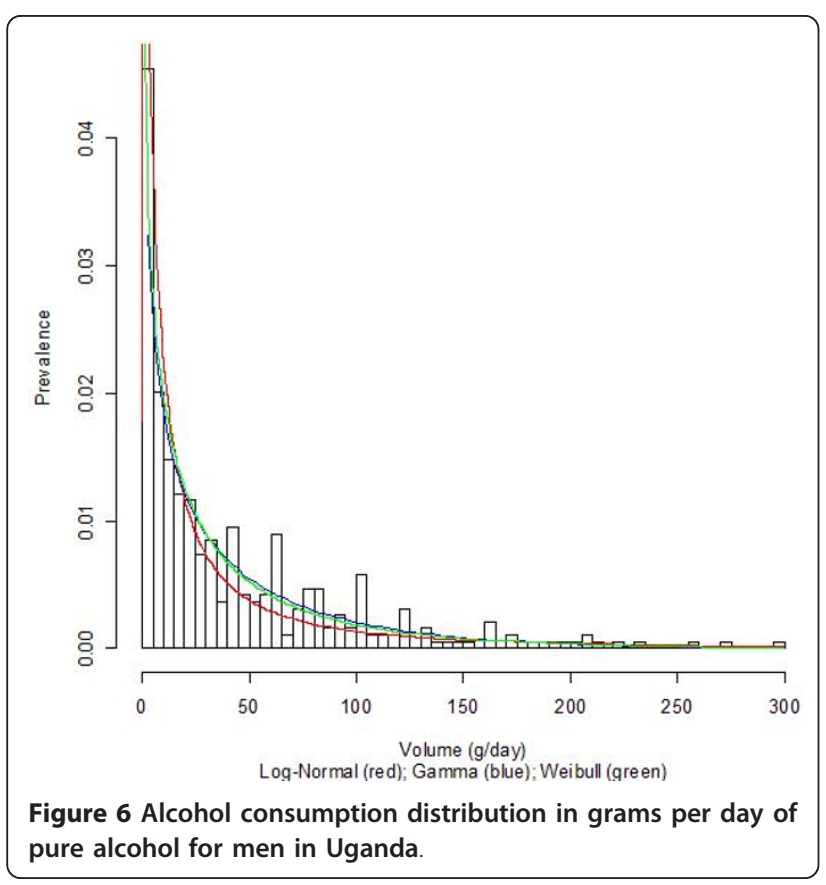

\section{Characterizing the alcohol consumption gamma distribution}

Based on data from GENACIS and STEPS, the mean daily average per capita alcohol consumption among drinkers was estimated to be 7.549 grams for women (the Gamma standard deviation was 9.862) and 18.292 grams for men (the Gamma standard deviation was 22.015) (see Table 10).

After analyzing the association between the Gamma mean and the Gamma standard deviation, a strong linear relationship was established. Analysis of the residuals of various general linear models led to the conclusion that a general linear model with a normal distribution and an identity link (i.e., a linear regression model) is the best possible model to characterize the relationship between the standard deviation of the Gamma distribution and the mean of the Gamma distribution. As a statistical interaction was determined to be present by gender for the relationship between the Gamma mean and the Gamma standard deviation, this linear relationship was modeled separately for men and for women.

Figures 7 and 8 illustrate the linear fit for women and men, respectively. The linear regressions indicate that a unit increase in mean alcohol consumption is associated with an increase of 1.258 (95\% CI: 1.223 to 1.293) in the standard deviation of the Gamma alcohol consumption distribution for women and 1.171 (95\% CI: 1.144 to 1.197$)$ in the standard deviation of the Gamma alcohol consumption distribution for men. Additionally, for women the linear regression indicated that $92.07 \%$ of the variation of the standard deviation of the Gamma distribution was explained by the mean, while for men $94.74 \%$ of the variation of the standard deviation of the Gamma distribution was explained by the mean.

Regression diagnostics indicated that there were some outliers. For women, two data points from Nigeria and one from Uganda were identified as influential observations, while for men, two observations in Germany and one in Nigeria were identified as influential observations. There was no indication of a lack of homoscedasticity for any of the regression models (Additional file 1).

\section{Discussion}

Both the Gamma and the Weibull distributions summarized the population distribution of average volume of alcohol consumption more accurately than did the Log-Normal distribution. Moreover, for the Gamma and Weibull distributions the ratio of mean to standard deviation was comparable across all countries, irrespective of drinking patterns and the survey measure used to measure alcohol consumption. Overall, both the Gamma and Weibull distributions yield similar PAFs and could 
Table 5 Proportion estimates for lifetime abstainers and former drinkers, as well as Population-Attributable Fraction (PAF) estimates for breast cancer using a categorical model and continuous models (Gamma, Log-Normal, and Weibull) for women

\begin{tabular}{|c|c|c|c|c|c|c|c|}
\hline \multirow[b]{2}{*}{ Country } & \multicolumn{2}{|c|}{ Proportions } & \multirow[b]{2}{*}{ Categorical } & \multicolumn{2}{|c|}{ PAF estimates } & \multirow[b]{2}{*}{ Weibull model } & \multirow[b]{2}{*}{$P A F_{\text {categorical }-P A F_{\text {gamma }}}$} \\
\hline & Abstainers & Former drinkers & & Gamma model & Log-Normal model & & \\
\hline Argentina & 0.06355 & 0.29933 & 0.14923 & 0.1354 & 0.15384 & 0.1362 & 0.01383 \\
\hline Australia & 0.04951 & 0.13319 & 0.10734 & 0.09444 & 0.12996 & 0.096 & 0.0129 \\
\hline Australia 1 & 0.12341 & 0.06414 & 0.08152 & 0.06024 & 0.07021 & 0.05996 & 0.02128 \\
\hline Austria & 0.17941 & 0.3288 & 0.16652 & 0.16302 & 0.1632 & 0.16338 & 0.0035 \\
\hline Belize & 0.59903 & 0.21449 & 0.10145 & 0.09595 & 0.09592 & 0.0951 & 0.0055 \\
\hline Brazil & 0.22741 & 0.36006 & 0.19526 & 0.18374 & 0.20113 & 0.18618 & 0.01152 \\
\hline Canada & 0.09532 & 0.16116 & 0.1189 & 0.10649 & 0.11779 & 0.10619 & 0.01241 \\
\hline Costa Rica & 0.19253 & 0.37923 & 0.16137 & 0.15162 & 0.15593 & 0.15135 & 0.00975 \\
\hline Czech Republic & 0.05538 & 0.14665 & 0.13325 & 0.11822 & 0.14643 & 0.11888 & 0.01503 \\
\hline Denmark & 0.00971 & 0.07061 & 0.10045 & 0.09091 & 0.12153 & 0.0911 & 0.00954 \\
\hline ECAS: Finland & 0.0748 & 0.00197 & 0.06369 & 0.0474 & 0.05292 & 0.04699 & 0.01629 \\
\hline ECAS: France & 0.27238 & 0 & 0.05939 & 0.04492 & 0.06499 & 0.04519 & 0.01447 \\
\hline ECAS: Germany & 0.18471 & 0 & 0.07463 & 0.04827 & 0.05679 & 0.0471 & 0.02636 \\
\hline ECAS: Italy & 0.21206 & 0.00195 & 0.08903 & 0.07422 & 0.11217 & 0.07535 & 0.01481 \\
\hline ECAS: Sweden & 0.132 & 0.002 & 0.04803 & 0.03386 & 0.03994 & 0.03388 & 0.01417 \\
\hline ECAS: UK & 0.14286 & 0 & 0.11594 & 0.10312 & 0.13957 & 0.10394 & 0.01282 \\
\hline Finland & 0.06491 & 0.04057 & 0.06973 & 0.05056 & 0.07463 & 0.05056 & 0.01917 \\
\hline France & 0.03552 & 0.41525 & 0.19287 & 0.18747 & 0.18762 & 0.18745 & 0.0054 \\
\hline Germany & 0.02588 & 0.03691 & 0.10094 & 0.08681 & 0.11568 & 0.08677 & 0.01413 \\
\hline Hungary & 0.17718 & 0.05964 & 0.06264 & 0.03701 & 0.0453 & 0.0363 & 0.02563 \\
\hline Iceland & 0.07396 & 0.08261 & 0.08375 & 0.06784 & 0.07546 & 0.0675 & 0.01591 \\
\hline India & 0.84014 & 0.10204 & 0.05502 & 0.05365 & 0.05764 & 0.05469 & 0.00137 \\
\hline Ireland & 0.23933 & 0.05937 & 0.1181 & 0.11259 & 0.1345 & 0.11288 & 0.00551 \\
\hline Isle of Man & 0.01838 & 0.11949 & 0.12723 & 0.1185 & 0.1757 & 0.12157 & 0.00873 \\
\hline Israel & 0.42882 & 0 & 0.04408 & 0.02458 & 0.0391 & 0.02325 & 0.0195 \\
\hline Italy & 0.19622 & 0.06094 & 0.10517 & 0.0899 & 0.11227 & 0.09029 & 0.01527 \\
\hline Japan & 0.15058 & 0.08415 & 0.0886 & 0.06775 & 0.09511 & 0.06877 & 0.02085 \\
\hline Kazakhstan & 0.10143 & 0.26307 & 0.13401 & 0.11568 & 0.12401 & 0.11479 & 0.01833 \\
\hline Mexico & 0.40553 & 0.17212 & 0.09092 & 0.07588 & 0.07463 & 0.07449 & 0.01504 \\
\hline Netherlands & 0.14467 & 0.17495 & 0.12055 & 0.11305 & 0.11531 & 0.11294 & 0.0075 \\
\hline Nicaragua & 0.50282 & 0.39336 & 0.16442 & 0.15622 & 0.15366 & 0.15459 & 0.0082 \\
\hline Nigeria & 0.56034 & 0.2298 & 0.16004 & 0.15402 & 0.16134 & 0.15696 & 0.00602 \\
\hline Norway & 0.04049 & 0.0757 & 0.08266 & 0.0662 & 0.08621 & 0.06621 & 0.01646 \\
\hline Peru & 0.08966 & 0.29951 & 0.13924 & 0.1245 & 0.12399 & 0.12449 & 0.01474 \\
\hline Spain & 0.22908 & 0.32427 & 0.1547 & 0.15056 & 0.17495 & 0.15131 & 0.00414 \\
\hline Sri Lanka & 0.8661 & 0.06949 & 0.03264 & 0.03012 & 0.02992 & 0.02995 & 0.00252 \\
\hline Sweden & 0.09666 & 0.1123 & 0.08539 & 0.06797 & 0.06996 & 0.06777 & 0.01742 \\
\hline Switzerland & 0.19806 & 0.06082 & 0.08298 & 0.07341 & 0.08702 & 0.0734 & 0.00957 \\
\hline Uganda & 0.36412 & 0.26649 & 0.15735 & 0.14658 & 0.1619 & 0.14889 & 0.01077 \\
\hline Uruguay & 0.17308 & 0.22596 & 0.12907 & 0.11302 & 0.12813 & 0.11289 & 0.01605 \\
\hline USA 1 & 0.10302 & 0.13854 & 0.10544 & 0.089 & 0.11203 & 0.08978 & 0.01644 \\
\hline USA 2 & 0.3263 & 0.18852 & 0.11255 & 0.09623 & 0.09806 & 0.09469 & 0.01632 \\
\hline USA 3 & 0.38019 & 0.05805 & 0.06399 & 0.04719 & 0.05318 & 0.04608 & 0.0168 \\
\hline
\end{tabular}

be used in descriptive alcohol epidemiology. Although not examined specifically, these outcomes would also apply to PAFs that are calculated when using a counterfactual scenario where alcohol consumption is decreased due to a policy or intervention such as taxation. Since the Weibull distribution is a more complicated distribution and less flexible than the Gamma distribution, and since it is possible to shift the Gamma distribution 
Table 6 Proportion estimates for lifetime abstainers and former drinkers, as well as Population-Attributable Fraction (PAF) estimates for diabetes using a categorical model and continuous models (Gamma, Log-Normal, and Weibull) for women

\begin{tabular}{|c|c|c|c|c|c|c|c|}
\hline \multirow[b]{2}{*}{ Country } & \multicolumn{2}{|c|}{ Proportions } & \multicolumn{4}{|c|}{ PAF estimates } & \multirow[b]{2}{*}{$P A F_{\text {categorical }-P A F_{\text {gamma }}}$} \\
\hline & Abstainers & Former drinkers & Categorical & Gamma model & Log-Normal model & Weibull model & \\
\hline Argentina & 0.06355 & 0.29933 & -0.14692 & -0.06787 & -0.05274 & -0.06333 & -0.07905 \\
\hline Australia & 0.04951 & 0.13319 & -0.24721 & -0.15762 & -0.12626 & -0.15022 & -0.08959 \\
\hline Australia 1 & 0.12341 & 0.06414 & -0.2699 & -0.16237 & -0.14117 & -0.15421 & -0.10753 \\
\hline Austria & 0.17941 & 0.3288 & -0.10003 & -0.09967 & -0.09292 & -0.09467 & -0.00036 \\
\hline Belize & 0.59903 & 0.21449 & -0.01794 & -0.00596 & -0.00215 & -0.0034 & -0.01198 \\
\hline Brazil & 0.22741 & 0.36006 & -0.05408 & -0.02384 & -0.01732 & -0.02246 & -0.03024 \\
\hline Canada & 0.09532 & 0.16116 & -0.21615 & -0.16259 & -0.13959 & -0.15557 & -0.05356 \\
\hline Costa Rica & 0.19253 & 0.37923 & -0.06097 & -0.00801 & -0.00214 & -0.00435 & -0.05296 \\
\hline Czech Republic & 0.05538 & 0.14665 & -0.23423 & -0.17322 & -0.14215 & -0.16336 & -0.06101 \\
\hline Denmark & 0.00971 & 0.07061 & -0.33046 & -0.26493 & -0.22239 & -0.26241 & -0.06553 \\
\hline ECAS: Finland & 0.0748 & 0.00197 & -0.32158 & -0.25101 & -0.22964 & -0.24296 & -0.07057 \\
\hline ECAS: France & 0.27238 & 0 & -0.25029 & -0.18164 & -0.15523 & -0.17478 & -0.06865 \\
\hline ECAS: Germany & 0.18471 & 0 & -0.2797 & -0.21639 & -0.19186 & -0.20633 & -0.06331 \\
\hline ECAS: Italy & 0.21206 & 0.00195 & -0.2856 & -0.21937 & -0.1826 & -0.21217 & -0.06623 \\
\hline ECAS: Sweden & 0.132 & 0.002 & -0.29211 & -0.20986 & -0.19889 & -0.20854 & -0.08225 \\
\hline ECAS: UK & 0.14286 & 0 & -0.30489 & -0.25529 & -0.22162 & -0.24719 & -0.0496 \\
\hline Finland & 0.06491 & 0.04057 & -0.29456 & -0.18499 & -0.16109 & -0.18021 & -0.10957 \\
\hline France & 0.03552 & 0.41525 & -0.10183 & -0.08985 & -0.08062 & -0.08479 & -0.01198 \\
\hline Germany & 0.02588 & 0.03691 & -0.33041 & -0.26864 & -0.22619 & -0.25848 & -0.06177 \\
\hline Hungary & 0.17718 & 0.05964 & -0.22547 & -0.08457 & -0.08059 & -0.07914 & -0.1409 \\
\hline Iceland & 0.07396 & 0.08261 & -0.26082 & -0.18598 & -0.16929 & -0.18056 & -0.07484 \\
\hline India & 0.84014 & 0.10204 & 0.0037 & 0.00412 & 0.00483 & 0.00417 & -0.00042 \\
\hline Ireland & 0.23933 & 0.05937 & -0.21416 & -0.21209 & -0.18943 & -0.20603 & -0.00207 \\
\hline Isle of Man & 0.01838 & 0.11949 & -0.27038 & -0.20513 & -0.15778 & -0.19787 & -0.06525 \\
\hline Israel & 0.42882 & 0 & -0.17003 & -0.09966 & -0.08491 & -0.09059 & -0.07037 \\
\hline Italy & 0.19622 & 0.06094 & -0.25978 & -0.2077 & -0.17787 & -0.20246 & -0.05208 \\
\hline Japan & 0.15058 & 0.08415 & -0.23347 & -0.11957 & -0.09699 & -0.10624 & -0.1139 \\
\hline Kazakhstan & 0.10143 & 0.26307 & -0.14039 & -0.04881 & -0.04103 & -0.0426 & -0.09158 \\
\hline Mexico & 0.40553 & 0.17212 & -0.08857 & -0.02026 & -0.01479 & -0.01363 & -0.06831 \\
\hline Netherlands & 0.14467 & 0.17495 & -0.18932 & -0.16501 & -0.15025 & -0.15897 & -0.02431 \\
\hline Nicaragua & 0.50282 & 0.39336 & 0.02923 & 0.03438 & 0.03458 & 0.03517 & -0.00515 \\
\hline Nigeria & 0.56034 & 0.2298 & -0.00892 & 0.00013 & -0.00065 & -0.00187 & -0.00905 \\
\hline Norway & 0.04049 & 0.0757 & -0.28376 & -0.18535 & -0.16146 & -0.18067 & -0.09841 \\
\hline Peru & 0.08966 & 0.29951 & -0.12528 & -0.04802 & -0.04493 & -0.04558 & -0.07726 \\
\hline Spain & 0.22908 & 0.32427 & -0.07944 & -0.05418 & -0.03553 & -0.05184 & -0.02526 \\
\hline Sri Lanka & 0.8661 & 0.06949 & -0.00659 & 0.00516 & 0.00598 & 0.00625 & -0.01175 \\
\hline Sweden & 0.09666 & 0.1123 & -0.23299 & -0.13662 & -0.12713 & -0.13302 & -0.09637 \\
\hline Switzerland & 0.19806 & 0.06082 & -0.24288 & -0.20449 & -0.18102 & -0.20067 & -0.03839 \\
\hline Uganda & 0.36412 & 0.26649 & -0.05139 & -0.02926 & -0.02312 & -0.02722 & -0.02213 \\
\hline Uruguay & 0.17308 & 0.22596 & -0.14518 & -0.07583 & -0.06006 & -0.06876 & -0.06935 \\
\hline USA 1 & 0.10302 & 0.13854 & -0.22157 & -0.12244 & -0.1 & -0.11227 & -0.09913 \\
\hline USA 2 & 0.3263 & 0.18852 & -0.11105 & -0.06216 & -0.05102 & -0.05505 & -0.04889 \\
\hline USA 3 & 0.38019 & 0.05805 & -0.16022 & -0.09638 & -0.08313 & -0.08908 & -0.06384 \\
\hline
\end{tabular}

upwards (necessary in modeling the burden of disease attributable to alcohol consumption), the Gamma distribution is the best distribution for modeling alcohol consumption.
Modeling survey alcohol consumption data alone without correcting the distribution for undercoverage will lead to inaccurate alcohol PAFs as self-reported survey data typically underestimate alcohol consumption based 
Table 7 Proportion estimates for lifetime abstainers and former drinkers, as well as Population-Attributable Fraction (PAF) estimates for diabetes using a categorical model and continuous models (Gamma, Log-Normal, and Weibull) for men

\begin{tabular}{|c|c|c|c|c|c|c|c|}
\hline \multirow[b]{2}{*}{ Country } & \multicolumn{2}{|c|}{ Proportions } & \multicolumn{4}{|c|}{ PAF estimates } & \multirow[b]{2}{*}{$P A F_{\text {categorical }-P A F_{\text {gamma }}}$} \\
\hline & Abstainers & Former drinkers & Categorical & Gamma model & Log-Normal model & Weibull model & \\
\hline Argentina & 0.02488 & 0.08209 & -0.06204 & -0.04912 & -0.03488 & -0.04748 & -0.01292 \\
\hline Australia & 0.04 & 0.078 & -0.06679 & -0.05195 & -0.03473 & -0.05064 & -0.01484 \\
\hline Austria & 0.07014 & 0.15774 & -0.03393 & -0.0344 & -0.03358 & -0.03185 & 0.00047 \\
\hline Belize & 0.20958 & 0.28647 & 0.01671 & 0.02142 & 0.02176 & 0.02153 & -0.00471 \\
\hline Brazil & 0.14516 & 0.2724 & 0.01291 & 0.01974 & 0.0221 & 0.01964 & -0.00683 \\
\hline Canada & 0.05019 & 0.1359 & -0.04406 & -0.03732 & -0.02801 & -0.03536 & -0.00674 \\
\hline Costa Rica & 0.07212 & 0.24279 & -0.00984 & 0.00218 & 0.01119 & 0.00484 & -0.01202 \\
\hline Czech Republic & 0.02653 & 0.07235 & -0.04347 & -0.03926 & -0.03536 & -0.04003 & -0.00421 \\
\hline Denmark & 0.00669 & 0.02899 & -0.08567 & -0.08015 & -0.06768 & -0.0783 & -0.00552 \\
\hline ECAS: Finland & 0.06855 & 0 & -0.08737 & -0.0843 & -0.07434 & -0.08173 & -0.00307 \\
\hline ECAS: France & 0.12632 & 0 & -0.07771 & -0.06634 & -0.05575 & -0.06515 & -0.01137 \\
\hline ECAS: Germany & 0.11828 & 0 & -0.08546 & -0.07494 & -0.06289 & -0.073 & -0.01052 \\
\hline ECAS: Italy & 0.107 & 0 & -0.08652 & -0.07515 & -0.06007 & -0.07519 & -0.01137 \\
\hline ECAS: Sweden & 0.07803 & 0 & -0.08431 & -0.07873 & -0.06794 & -0.07597 & -0.00558 \\
\hline ECAS: UK & 0.10422 & 0 & -0.06259 & -0.04982 & -0.05368 & -0.04976 & -0.01277 \\
\hline Finland & 0.03181 & 0.05196 & -0.07492 & -0.06375 & -0.04797 & -0.06205 & -0.01117 \\
\hline France & 0.01975 & 0.2008 & -0.02168 & -0.0214 & -0.01805 & -0.02032 & -0.00028 \\
\hline Germany & 0.01415 & 0.03101 & -0.08136 & -0.07386 & -0.05941 & -0.07326 & -0.0075 \\
\hline Hungary & 0.04696 & 0.04052 & -0.07032 & -0.0531 & -0.03804 & -0.04984 & -0.01722 \\
\hline Iceland & 0.04117 & 0.09005 & -0.06259 & -0.05392 & -0.04428 & -0.05279 & -0.00867 \\
\hline India & 0.56138 & 0.10816 & 0.00549 & 0.00725 & 0.00506 & 0.0058 & -0.00176 \\
\hline Ireland & 0.16501 & 0.06958 & -0.03008 & -0.02443 & -0.03142 & -0.02394 & -0.00565 \\
\hline Isle of Man & 0.00885 & 0.06195 & -0.05799 & -0.0442 & -0.03528 & -0.04466 & -0.01379 \\
\hline Israel & 0.23209 & 0 & -0.06315 & -0.048 & -0.03712 & -0.04455 & -0.01515 \\
\hline Italy & 0.05808 & 0.03977 & -0.07456 & -0.06762 & -0.05524 & -0.06853 & -0.00694 \\
\hline Japan & 0.04869 & 0.04148 & -0.06659 & -0.04611 & -0.03092 & -0.04448 & -0.02048 \\
\hline Kazakhstan & 0.04267 & 0.21336 & -0.01315 & -0.0054 & -0.0001 & -0.00513 & -0.00775 \\
\hline Mexico & 0.09404 & 0.13644 & -0.03411 & -0.01966 & -0.01217 & -0.01758 & -0.01445 \\
\hline Netherlands & 0.06032 & 0.10269 & -0.05643 & -0.0539 & -0.04592 & -0.05264 & -0.00253 \\
\hline Nicaragua & 0.12052 & 0.45114 & 0.05098 & 0.0533 & 0.05278 & 0.05332 & -0.00232 \\
\hline Nigeria & 0.41863 & 0.18445 & 0.0144 & 0.0159 & 0.01485 & 0.01489 & -0.0015 \\
\hline Norway & 0.02321 & 0.06286 & -0.06847 & -0.06023 & -0.04747 & -0.05749 & -0.00824 \\
\hline Peru & 0.03488 & 0.14147 & -0.04085 & -0.02909 & -0.02334 & -0.02555 & -0.01176 \\
\hline Spain & 0.09172 & 0.23378 & -0.0116 & -0.0071 & 0.00214 & -0.00672 & -0.0045 \\
\hline Sri Lanka & 0.19403 & 0.27032 & 0.01625 & 0.02531 & 0.02578 & 0.02476 & -0.00906 \\
\hline Sweden & 0.05049 & 0.06481 & -0.06583 & -0.04793 & -0.04038 & -0.0462 & -0.0179 \\
\hline Switzerland & 0.06763 & 0.0412 & -0.07542 & -0.07214 & -0.06481 & -0.06895 & -0.00328 \\
\hline Uganda & 0.28611 & 0.18889 & 0.01732 & 0.01764 & 0.01246 & 0.01555 & -0.00032 \\
\hline Uruguay & 0.04787 & 0.14096 & -0.03916 & -0.02318 & -0.01523 & -0.02209 & -0.01598 \\
\hline USA 2 & 0.16125 & 0.1617 & -0.02577 & -0.01383 & -0.0064 & -0.01152 & -0.01194 \\
\hline USA 3 & 0.26011 & 0.0707 & -0.04069 & -0.02818 & -0.02105 & -0.0261 & -0.01251 \\
\hline USA 2 & 0.3263 & 0.18852 & -0.11105 & -0.06216 & -0.05102 & -0.05505 & -0.04889 \\
\hline USA 3 & 0.38019 & 0.05805 & -0.16022 & -0.09638 & -0.08313 & -0.08908 & -0.06384 \\
\hline
\end{tabular}

on sales or taxation (e.g., [26]). In other words, alcohol surveys often do not accurately represent the population due to undercoverage where some members of the population are inadequately represented (or excluded) or due to response bias [30]. Accordingly, a method must be developed that will shift the exposure distribution so that it is consistent with per capita consumption data in order to correct for survey bias and allow for a more accurate 
Table 8 Proportion estimates for lifetime abstainers and former drinkers, as well as Population-Attributable Fraction (PAF) estimates for pancreatitis using a categorical model and continuous models (Gamma, Log-Normal, and Weibull) for women

\begin{tabular}{|c|c|c|c|c|c|c|c|}
\hline \multirow[b]{2}{*}{ Country } & \multicolumn{2}{|c|}{ Proportions } & \multicolumn{4}{|c|}{ PAF estimates } & \multirow[b]{2}{*}{$P A F_{\text {categorical }-P A F_{\text {gamma }}}$} \\
\hline & Abstainers & Former drinkers & Categorical & Gamma model & Log-Normal model & Weibull model & \\
\hline Argentina & 0.02488 & 0.08209 & -0.06204 & -0.04912 & -0.03488 & -0.04748 & -0.01292 \\
\hline Australia & 0.04 & 0.078 & -0.06679 & -0.05195 & -0.03473 & -0.05064 & -0.01484 \\
\hline Austria & 0.07014 & 0.15774 & -0.03393 & -0.0344 & -0.03358 & -0.03185 & 0.00047 \\
\hline Belize & 0.20958 & 0.28647 & 0.01671 & 0.02142 & 0.02176 & 0.02153 & -0.00471 \\
\hline Brazil & 0.14516 & 0.2724 & 0.01291 & 0.01974 & 0.0221 & 0.01964 & -0.00683 \\
\hline Canada & 0.05019 & 0.1359 & -0.04406 & -0.03732 & -0.02801 & -0.03536 & -0.00674 \\
\hline Costa Rica & 0.07212 & 0.24279 & -0.00984 & 0.00218 & 0.01119 & 0.00484 & -0.01202 \\
\hline Czech Republic & 0.02653 & 0.07235 & -0.04347 & -0.03926 & -0.03536 & -0.04003 & -0.00421 \\
\hline Denmark & 0.00669 & 0.02899 & -0.08567 & -0.08015 & -0.06768 & -0.0783 & -0.00552 \\
\hline ECAS: Finland & 0.06855 & 0 & -0.08737 & -0.0843 & -0.07434 & -0.08173 & -0.00307 \\
\hline ECAS: France & 0.12632 & 0 & -0.07771 & -0.06634 & -0.05575 & -0.06515 & -0.01137 \\
\hline ECAS: Germany & 0.11828 & 0 & -0.08546 & -0.07494 & -0.06289 & -0.073 & -0.01052 \\
\hline ECAS: Italy & 0.107 & 0 & -0.08652 & -0.07515 & -0.06007 & -0.07519 & -0.01137 \\
\hline ECAS: Sweden & 0.07803 & 0 & -0.08431 & -0.07873 & -0.06794 & -0.07597 & -0.00558 \\
\hline ECAS: UK & 0.10422 & 0 & -0.06259 & -0.04982 & -0.05368 & -0.04976 & -0.01277 \\
\hline Finland & 0.03181 & 0.05196 & -0.07492 & -0.06375 & -0.04797 & -0.06205 & -0.01117 \\
\hline France & 0.01975 & 0.2008 & -0.02168 & -0.0214 & -0.01805 & -0.02032 & -0.00028 \\
\hline Germany & 0.01415 & 0.03101 & -0.08136 & -0.07386 & -0.05941 & -0.07326 & -0.0075 \\
\hline Hungary & 0.04696 & 0.04052 & -0.07032 & -0.0531 & -0.03804 & -0.04984 & -0.01722 \\
\hline Iceland & 0.04117 & 0.09005 & -0.06259 & -0.05392 & -0.04428 & -0.05279 & -0.00867 \\
\hline India & 0.56138 & 0.10816 & 0.00549 & 0.00725 & 0.00506 & 0.0058 & -0.00176 \\
\hline Ireland & 0.16501 & 0.06958 & -0.03008 & -0.02443 & -0.03142 & -0.02394 & -0.00565 \\
\hline Isle of Man & 0.00885 & 0.06195 & -0.05799 & -0.0442 & -0.03528 & -0.04466 & -0.01379 \\
\hline Israel & 0.23209 & 0 & -0.06315 & -0.048 & -0.03712 & -0.04455 & -0.01515 \\
\hline Italy & 0.05808 & 0.03977 & -0.07456 & -0.06762 & -0.05524 & -0.06853 & -0.00694 \\
\hline Japan & 0.04869 & 0.04148 & -0.06659 & -0.04611 & -0.03092 & -0.04448 & -0.02048 \\
\hline Kazakhstan & 0.04267 & 0.21336 & -0.01315 & -0.0054 & -0.0001 & -0.00513 & -0.00775 \\
\hline Mexico & 0.09404 & 0.13644 & -0.03411 & -0.01966 & -0.01217 & -0.01758 & -0.01445 \\
\hline Netherlands & 0.06032 & 0.10269 & -0.05643 & -0.0539 & -0.04592 & -0.05264 & -0.00253 \\
\hline Nicaragua & 0.12052 & 0.45114 & 0.05098 & 0.0533 & 0.05278 & 0.05332 & -0.00232 \\
\hline Nigeria & 0.41863 & 0.18445 & 0.0144 & 0.0159 & 0.01485 & 0.01489 & -0.0015 \\
\hline Norway & 0.02321 & 0.06286 & -0.06847 & -0.06023 & -0.04747 & -0.05749 & -0.00824 \\
\hline Peru & 0.03488 & 0.14147 & -0.04085 & -0.02909 & -0.02334 & -0.02555 & -0.01176 \\
\hline Spain & 0.09172 & 0.23378 & -0.0116 & -0.0071 & 0.00214 & -0.00672 & -0.0045 \\
\hline Sri Lanka & 0.19403 & 0.27032 & 0.01625 & 0.02531 & 0.02578 & 0.02476 & -0.00906 \\
\hline Sweden & 0.05049 & 0.06481 & -0.06583 & -0.04793 & -0.04038 & -0.0462 & -0.0179 \\
\hline Switzerland & 0.06763 & 0.0412 & -0.07542 & -0.07214 & -0.06481 & -0.06895 & -0.00328 \\
\hline Uganda & 0.28611 & 0.18889 & 0.01732 & 0.01764 & 0.01246 & 0.01555 & -0.00032 \\
\hline Uruguay & 0.04787 & 0.14096 & -0.03916 & -0.02318 & -0.01523 & -0.02209 & -0.01598 \\
\hline USA 2 & 0.16125 & 0.1617 & -0.02577 & -0.01383 & -0.0064 & -0.01152 & -0.01194 \\
\hline USA 3 & 0.26011 & 0.0707 & -0.04069 & -0.02818 & -0.02105 & -0.0261 & -0.01251 \\
\hline USA 2 & 0.3263 & 0.18852 & -0.11105 & -0.06216 & -0.05102 & -0.05505 & -0.04889 \\
\hline USA 3 & 0.38019 & 0.05805 & -0.16022 & -0.09638 & -0.08313 & -0.08908 & -0.06384 \\
\hline
\end{tabular}

estimation of the true alcohol consumption distribution and for an accurate comparison of the alcohol-attributable burden of disease across countries.
Given the relationship between the mean and the standard deviation of alcohol consumption [15], modeling alcohol consumption using the Gamma distribution, up- 
Table 9 Proportion estimates for lifetime abstainers and former drinkers, as well as Population-Attributable Fraction (PAF) estimates for pancreatitis using a categorical model and continuous models (Gamma, Log-Normal, and Weibull) for men

\begin{tabular}{|c|c|c|c|c|c|c|c|}
\hline \multirow[b]{2}{*}{ Country } & \multicolumn{2}{|l|}{ Proportions } & \multicolumn{5}{|c|}{ PAF estimates } \\
\hline & Abstainers & Former drinkers & Categorical & Gamma model & Log-Normal model & Weibull model & $P A F_{\text {categorical - }} P A F_{\text {gamma }}$ \\
\hline Argentina & 0.02488 & 0.08209 & 0.22296 & 0.15927 & 0.43723 & 0.20014 & 0.06369 \\
\hline Australia & 0.04 & 0.078 & 0.08654 & 0.08482 & 0.38073 & 0.10451 & 0.00172 \\
\hline Austria & 0.07014 & 0.15774 & 0.28936 & 0.22295 & 0.35679 & 0.2301 & 0.06641 \\
\hline Belize & 0.20958 & 0.28647 & 0.33325 & 0.24985 & 0.33703 & 0.27395 & 0.0834 \\
\hline Brazil & 0.14516 & 0.2724 & 0.36261 & 0.29194 & 0.39178 & 0.32264 & 0.07067 \\
\hline Canada & 0.05019 & 0.1359 & 0.21733 & 0.13226 & 0.33792 & 0.15511 & 0.08507 \\
\hline Costa Rica & 0.07212 & 0.24279 & 0.12691 & 0.10615 & 0.29474 & 0.14666 & 0.02076 \\
\hline Czech Republic & 0.02653 & 0.07235 & 0.45021 & 0.44383 & 0.59431 & 0.46265 & 0.00638 \\
\hline Denmark & 0.00669 & 0.02899 & 0.21317 & 0.1266 & 0.36293 & 0.13557 & 0.08657 \\
\hline ECAS: Finland & 0.06855 & 0 & 0.15448 & 0.09867 & 0.28828 & 0.1085 & 0.05581 \\
\hline ECAS: France & 0.12632 & 0 & 0.27896 & 0.19496 & 0.44157 & 0.22458 & 0.084 \\
\hline ECAS: Germany & 0.11828 & 0 & 0.11683 & 0.07036 & 0.27456 & 0.07978 & 0.04647 \\
\hline ECAS: Italy & 0.107 & 0 & 0.14476 & 0.13578 & 0.42278 & 0.1422 & 0.00898 \\
\hline ECAS: Sweden & 0.07803 & 0 & 0.14909 & 0.04825 & 0.19429 & 0.05417 & 0.10084 \\
\hline ECAS: UK & 0.10422 & 0 & 0.52217 & 0.49318 & 0.58899 & 0.50824 & 0.02899 \\
\hline Finland & 0.03181 & 0.05196 & 0.12555 & 0.07766 & 0.33705 & 0.0898 & 0.04789 \\
\hline France & 0.01975 & 0.2008 & 0.24059 & 0.22953 & 0.39322 & 0.24816 & 0.01106 \\
\hline Germany & 0.01415 & 0.03101 & 0.18565 & 0.16192 & 0.44023 & 0.17239 & 0.02373 \\
\hline Hungary & 0.04696 & 0.04052 & 0.08571 & 0.0504 & 0.29853 & 0.07345 & 0.03531 \\
\hline Iceland & 0.04117 & 0.09005 & 0.0527 & 0.04367 & 0.15151 & 0.04482 & 0.00903 \\
\hline India & 0.56138 & 0.10816 & 0.40834 & 0.36381 & 0.36933 & 0.36204 & 0.04453 \\
\hline Ireland & 0.16501 & 0.06958 & 0.58943 & 0.51065 & 0.5712 & 0.52348 & 0.07878 \\
\hline Isle of Man & 0.00885 & 0.06195 & 0.41981 & 0.3877 & 0.57684 & 0.42486 & 0.03211 \\
\hline Israel & 0.23209 & 0 & 0.15418 & 0.05803 & 0.26452 & 0.09695 & 0.09615 \\
\hline taly & 0.05808 & 0.03977 & 0.13931 & 0.18626 & 0.45169 & 0.18221 & -0.04695 \\
\hline Japan & 0.04869 & 0.04148 & 0.25401 & 0.2705 & 0.53622 & 0.35619 & -0.01649 \\
\hline Kazakhstan & 0.04267 & 0.21336 & 0.42465 & 0.27561 & 0.43974 & 0.30884 & 0.14904 \\
\hline Mexico & 0.09404 & 0.13644 & 0.29837 & 0.18325 & 0.36482 & 0.23945 & 0.11512 \\
\hline Netherlands & 0.06032 & 0.10269 & 0.13115 & 0.11909 & 0.29457 & 0.12463 & 0.01206 \\
\hline Nicaragua & 0.12052 & 0.45114 & 0.35959 & 0.24862 & 0.30616 & 0.26612 & 0.11097 \\
\hline Nigeria & 0.41863 & 0.18445 & 0.35308 & 0.37914 & 0.43234 & 0.39043 & -0.02606 \\
\hline Norway & 0.02321 & 0.06286 & 0.13943 & 0.06723 & 0.2652 & 0.07835 & 0.0722 \\
\hline Peru & 0.03488 & 0.14147 & 0.17245 & 0.04226 & 0.05929 & 0.04328 & 0.13019 \\
\hline Spain & 0.09172 & 0.23378 & 0.22602 & 0.19353 & 0.43043 & 0.20917 & 0.03249 \\
\hline$\underline{\text { Sri Lanka }}$ & 0.19403 & 0.27032 & 0.36577 & 0.31928 & 0.36454 & 0.33162 & 0.04649 \\
\hline Sweden & 0.05049 & 0.06481 & 0.03966 & 0.02675 & 0.08574 & 0.02787 & 0.01291 \\
\hline Switzerland & 0.06763 & 0.0412 & 0.25281 & 0.12628 & 0.30113 & 0.14007 & 0.12653 \\
\hline Uganda & 0.28611 & 0.18889 & 0.56306 & 0.5551 & 0.55585 & 0.55323 & 0.00796 \\
\hline Uruguay & 0.04787 & 0.14096 & 0.39759 & 0.24 & 0.43627 & 0.2895 & 0.15759 \\
\hline USA 2 & 0.16125 & 0.1617 & 0.18083 & 0.11673 & 0.28693 & 0.15662 & 0.0641 \\
\hline USA 3 & 0.26011 & 0.0707 & 0.2473 & 0.11757 & 0.28915 & 0.15812 & 0.12973 \\
\hline
\end{tabular}


Table 10 Descriptive statistics of the alcohol surveys from 66 countries

\begin{tabular}{llllll}
\hline & $\begin{array}{l}\text { Number of } \\
\text { estimates }\end{array}$ & $\begin{array}{l}\text { Empirical } \\
\text { mean }\end{array}$ & $\begin{array}{l}\text { Empirical standard } \\
\text { deviation }\end{array}$ & $\begin{array}{l}\text { Gamma distribution } \\
\text { mean }\end{array}$ & $\begin{array}{l}\text { Gamma distribution standard } \\
\text { deviation }\end{array}$ \\
\hline Women & 422 & 7.55 & 12.63 & 7.55 & 9.86 \\
\hline Men & 429 & 18.29 & 25.60 & 18.29 & 22.01 \\
\hline Total & 851 & 12.96 & 19.17 & 12.96 & 15.99 \\
\hline
\end{tabular}

estimating this distribution using the relationship between the mean and the standard deviation, and using per capita consumption data, allows us to correct for the biases that lead to undercoverage (for specifics on the upshifting methods see [15]) and allows for the estimation of the distribution of alcohol consumption in a country as if it were measured by a survey with a much higher coverage rate. Additionally, based on the relationship between the mean and the standard deviation of the alcohol consumption Gamma distribution, we can use the mean alcohol consumption from sales and taxation data to obtain the $\kappa$ and $\theta$ parameters for the alcohol exposure distribution for those countries where no survey data exist. Due to great variations in the populations surveyed, and in the sampling frame, response rate, and coverage rate for each of the individual surveys within the main survey groups of GENACIS, ECAS, and STEPS, our observations that alcohol consumption can best be modeled through a Gamma distribution and that the mean is highly correlated with the standard deviation of the alcohol consumption Gamma distribution indicate that these results are applicable to a wide range of countries and are valid for population surveys that use different methodologies.

An interesting finding from our study was the identification as outliers of some of the observations from Nigeria. This could be due to multiple factors. The number of observations from Nigeria upon which the mean and the standard deviation of the alcohol consumption Gamma distribution are based are fewer than the number of observations from other countries. A further factor is that the relationship between the mean and standard deviation of the alcohol consumption Gamma distribution for Nigeria may be different when compared to other countries. Given that only some age groups in Nigeria were identified by the regression diagnostics as outliers, it is very likely that these outliers were due to the low number of individuals surveyed in Nigeria. Future research will focus on modeling alcohol consumption by global region (such as by using the 2005 Comparative Risk Assessment regions [44]) to see if there are regional differences in the relationship between the mean and the standard deviation of the alcohol consumption Gamma distribution.
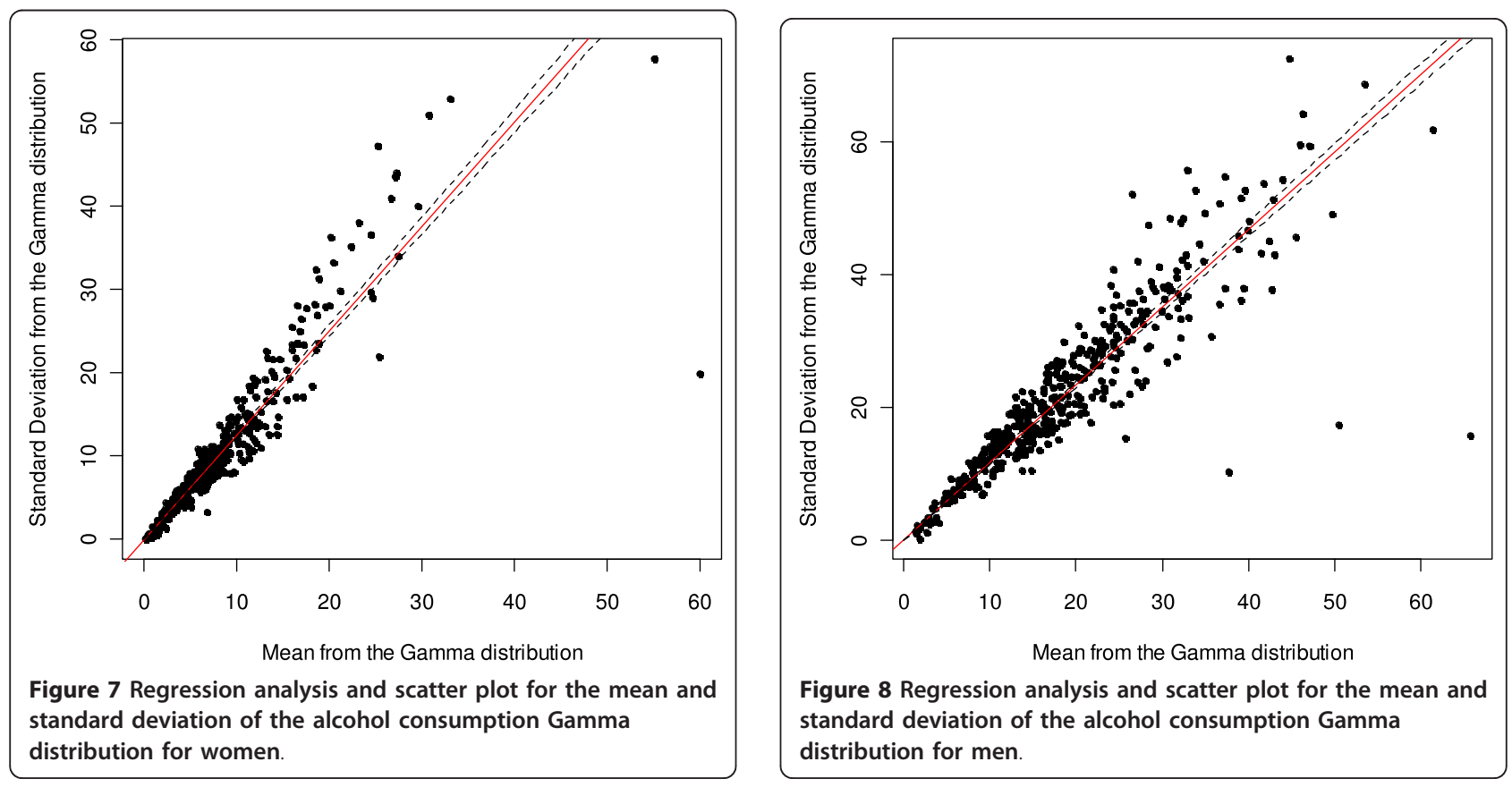


\section{Conclusion}

When comparing the Log-Normal, Weibull, and Gamma distributions to calculate average consumption of alcohol, the Gamma distribution and the Weibull distribution outperform the Log-Normal distribution in fitting the empirical consumption distribution. Of these two distributions, the Gamma distribution appears to be the best choice for modeling as it has two parameters that can easily be shifted to make the fit more compatible with the per capita consumption data, thus making it possible to estimate the exposure distribution of countries with only aggregate per capita consumption reported, as long as prevalence of abstention is known (see [15]). Thus, shifting the mean upwards is possible, as the Gamma distribution can be described by two parameters (mean and standard deviation), which empirically can be reduced to one, as a large degree of variance of the standard deviation of the alcohol consumption Gamma distribution is explained by the mean alcohol consumption. Accurate modeling of alcohol consumption as an upshifted distribution will provide public health decision-makers with accurate data to assess the impact of alcohol consumption within and across countries and will aid in determining public health priorities and where to allocate resources.

\section{Additional material}

\section{Additional file 1: Web Appendix. This web appendix includes}

parameter estimates using non-truncated data for women and men from Log-Normal, Gamma, and Weibull models, proportion estimates for lifetime abstainers and former drinkers, as well as Population Attributable Fraction (PAF) estimates for breast cancer, diabetes, pancreatitis using a categorical model and a continuous model. Count, proportion and weighted global proportion estimates for women and men drinkers that drink $\leq 96 \mathrm{~g} /$ day, $>96 \mathrm{~g} / \mathrm{day}, \leq 120 \mathrm{~g} /$ day, and $>120 \mathrm{~g} /$ day were also included. Proportion estimates for the decomposition of alcohol Population Attributable Fraction (PAF) are listed for breast cancer and pancreatitis consisting of drinkers that drink $\leq 96 \mathrm{~g} /$ day and $>96 \mathrm{~g} /$ day, $\leq 120 \mathrm{~g} /$ day and $>120 \mathrm{~g} / \mathrm{day}, \leq 150 \mathrm{~g} /$ day and $>150 \mathrm{~g} / \mathrm{day}$, and $\leq 200$ $\mathrm{g} /$ day and $>200 \mathrm{~g} /$ day using a continuous model (Gamma, Log-Normal, and Weibull) for women and men.

\section{Acknowledgements}

This paper uses data from Gender, Alcohol and Culture: An International Study (GENACIS). GENACIS is a collaborative international project affiliated with the Kettil Bruun Society for Social and Epidemiological Research on Alcohol and coordinated by GENACIS partners from the University of North Dakota, the University of Southern Denmark, the Charite University Medicine Berlin, the Pan American Health Organization (PAHO), and the Swiss Institute for the Prevention of Alcohol and Drug Problems. Support for aspects of the project comes from the World Health Organization (WHO), the Quality of Life and Management of Living Resources Programme of the European Commission (Concerted Action QLG4-CT-2001-0196), the United States National Institute on Alcohol Abuse and Alcoholism/National Institutes of Health (Grant Numbers R21 AA012941 and R01 AA015775), the German Federal Ministry of Health, PAHO, and Swiss national funds. Support for individual country surveys was provided by government agencies and other national sources. The study leaders and funding sources for datasets used in this study are:

Argentina (Myriam Munné, WHO); Australia (Jillian Fleming, National Campaign Against Drug Abuse, National Centre for Epidemiology and Population Health, Australian National University; Paul Dietze, National Health and Medical Research Council (Grant 398500)); Austria (Irmgard EisenbachStangl, Boltzmann Institute); Belize (Claudina Cayetano, PAHO); Brazil (Florence Kerr-Correa; Foundation for the Support of Sao Paulo State Research (Fundação de Amparo a Pesquisa do Estado de São Paulo, FAPESP) (Grant 01/03150-6)); Canada (Kate Graham; Canadian Institutes of Health Research (CIHR)); Costa Rica (Julio Bejarano, WHO); Czech Republic (Ladislav Csémy, Ministry of Health (Grant MZ 23752)); Denmark (Kim Bloomfield, Sygekassernes Helsefond; Danish Medical Research Council); Finland (Pia Mäkelä, National Research and Development Centre for Welfare and Health (STAKES)); France (Francois Beck, National Institute of Prevention and Heath Education (INPES)); Germany (Ludwig Kraus, German Federal Ministry of Health (BMGS) and in cooperation with the Institute for Therapy Research, Munich, Germany); Hungary (Zsuzsanna Elekes, Ministry of Youth and Sport); Iceland (Hildigunnur Ólafsdóttir, Alcohol and Drug Abuse Prevention Council, Public Health Institute of Iceland, Reykjavík, Iceland); India (Vivek Benegal, WHO); Ireland (Ann Hope, Department of Health and Children (HPU)); Isle of Man (Martin Plant, Moira Plant, Isle of Man Medical Research Council; University of the West of England, Bristol); Israel (Giora Rahav, Meir Teichman, Anti Drugs Authority of Israel); Italy (Allaman Allamani, Centro Alcologico, Florence Health Agency, Regional Health Agency of Tuscany); Japan (Shinji Shimizu, Japan Society for the Promotion of Science (Grant 13410072)); Kazakhstan (Bedel Sarbayev, WHO); Mexico (Maria-Elena MedinaMora, Ministry of Health, Mexico, Office of Antinarcotics Issues; US Embassy in Mexico; National Institute of Psychiatry; National Council Against Addictions; General; Directorate of Epidemiology and Sub-secretary of Prevention and Control of Diseases, Ministry of Health, Mexico); Netherlands (Ronald Knibbe, Ministry of Health and Welfare of the Netherlands); Nicaragua (Jose Trinidad Caldera, PAHO); Nigeria (Akanidomolbanga, WHO); Norway (Sturla Nordlund, Norwegian Institute for Alcohol and Drug Research); Peru (Marina Piazza, PAHO); Spain (Juan C. Valderrama, Dirección General de Atención a la Dependencia, Conselleria de Sanidad, Generalitat Valenciana; Comisionado do Plan de Galicia sobre Drogas, Conselleria de Sanidade, Xunta de Galicia; Dirección General de Drogodependencias y Servicios Sociales, Gobierno de Cantabria); Sri Lanka (Siri Hettige, WHO); Sweden (Karin Bergmark, Ministry for Social Affairs and Health, Sweden); Switzerland (Gerhard Gmel, Swiss Federal Office for Education and Science (Contract 01.0366); Swiss Federal Statistical Office; Uganda (Nazarius Mbona Tumwesigye, WHO); Uruguay (Raquel Magri, WHO); UK (Martin Plant, Moira Plant, Alcohol Education and Research Council; European Forum for Responsible Drinking; University of the West of England, Bristol); US (Sharon C. Wilsnack, Richard W. Wilsnack, Thomas Greenfield, National Institute on Alcohol Abuse and Alcoholism/National Institutes of Health (Grants; R01 AA015775 and R21 AA012941; P50 AA05595; P50 AA05595); University of North Dakota (Subcontract No. 254, Amendment No.2 UND Fund 41530425)).

This paper also uses data from STEPwise approach to Surveillance (STEPS). We would like to thank the following individuals who have supported the concept of STEPS:

Hyppolyte Agbuton, Kingsley Akinroye, Annette Akinsete, Tim Albion, Julia Alfred, Ala Alwan, Ezzat Amine, Krishnan Anand, Craig Anderson, Martha Anker, N.K. Arora, Kjell Asplund, Nahla Baba, Albert Barcelo, Abdul Bari Abdulla, Kidist Bartolomeos, Robert Beaglehole, Mohammed Belhocine, Lydia Bendib, Rafael Bengoa, Ruth Berkelman, Pedro Mas Bermejo, I.P. Bhagwat, Tran Huu Bich, Steve Blair, Leigh Blizzard, Martin Bobak, Pascal Bouvet, Debbie Bradshaw, Joanna Broad, Fiona Bull, Peter Byass, Peter Callan, Dennis Calvert, Lucimar Cannon, Barbro Carlsson, Vikashni Chand, Jie Chen, Bernard Choi, Miriam Claeson, Alberto Concha-Eastman, Stephen Corber, Margaret Cornelius, Vera Costa e Silva, Albertino Damasceno, Isabel Danel, Niklas Danielsson, lan Darnton Hill, N.G. Desai, Abolghassem Djazayery, Hind Djerrari, Annette Dobson, Kathy Douglas, Terry Dwyer, Joan Dzenowagis, Anders Emmelin, Alfredo Espinosa Brito, Sarah Faletoese, Anna Ferro-Luzzi, Antonio Filipe, Noela Fitzgerald, Limbo Fiu, Sunia Foliaki, Monica Fong, Terrence Forrester, Jayne Fryer, Gauden Galea, Deborah Galuska, Elize Gershater, Jean-Pierre Gervaisoni, Mariano Bonet Gorbea, Vilnius Grabauskas, Robert Granger, P.C. Gupta, Rajeev Gupta, Djohar Hannoun, Toshihiko Hasegawa, Richard Heller, Susilowati Herman, Dionisio Herreira, Helen 
Hermann, John Jabbour, Samer Jabbour, Rally Jim, S.K. Jindal, Abraham Joseph, Prashant Joshi, Umesh Kapil, S.K. Kapoor, Oussama Khatib, Robert Kim-Farley, Hilary King, Makeleta Koloi, Lingzhi Kong, Andrea Kriska, Etienne Krug, Thomas Kurian, Kerry Kutch, Kari Kuulasmaa, Louise Hayes, Gael Kernen, Stevenson Kuartei, Justina Langidrik, H. Latiri, Jerzy Leowski, Dominique LeFévre, Xinhua Li, L. Lili'o, Kipier Lippwe, Alan Lopez, Heather MacDonald, Nancy Macdonald, Sarah MacFarlane, Judith Mackay, Nejma Macklai, U.A. Maga, Blerta Maliqi, Jean-Claude Mbanya, Tony Mbewu, Laura McDougall, David McQueen, Shanthi Mendis, George Mensah, Airambiata Metai, Dan Miller, Anoop Misra, V. Mohan, Maristela Monteiro, Alfredo Morabia, D. McDonald Mtotha, David McQueen, Ferdinand Mugusi, Gano Mwarewo, Shakila Naidu, Richard Nesbit, Angela Newill, Nawi Ng, Chizuru Nishida, Robyn Norton, Ayoade Olatunbosun-Alakija, Pedro Ordunez, Stipe Orešković, Fred Paccaud, Arvind Pandey, Lili Pasat, Margie Peden, Rachel Pedersen, Janina Petkeviciene, Pirjo Pietinen, Barry Popkin, Rimina Potemkinov, Viliami Puloka, Pekka Puska, Jan Pryor, Mahmudur Rahman, Sawat Ramaboot, Lars Ramstrom, K Srinath Reddy, Peter Redert, Nina Rehn, Claude Renaud, Sylvia Robles, Paz Rodriquez, Gojka Roglic, Salanieta Taka Saketa, Susana Sans, Shekhar Saxena, Cristina Schneider, Jimaima Schultz, Cecilia Sepulveda, Bella Shah, Aushra Shatchkute, Prakash Shetty, N. Short, Padam Singh, S.K. Sinha, Michael Sjöström, Seilini Soakai, Lakshmi Somatunga, C. Sookram, Soeharsono Soemantri, Harley John Stanton, Krisela Steyn, Kathleen Strong, T.N. Sugathan, Hirotu Suzuki, Karen Tairea, Julita Tellei, K.R. Thankappan, Benete Tokanang, Hanna Tolonen, Steve Tollman, O. Tommaso, Thomas Truelsen, Nigel Unwin, Ulla Uusitalo, Cherian, Barbora Vozarova, Godfrey Waidubu, Stig Wall, Lepani Waqatakirewa, Franklin White, Derek Yach, Zaida Yadon, Mabel Yap, Helena Zabina, Paul Zimmet. Support from the Governments of Australia, the Netherlands, Sweden, and the United Kingdom toward the development and implementation of the WHO STEPwise approach to Surveillance (STEPS) is also gratefully acknowledged.

\section{Author details}

${ }^{1}$ Centre for Addiction and Mental Health (CAMH), Toronto, Canada. ${ }^{2}$ Department of Statistics, University of Toronto, Toronto, Canada. ${ }^{3}$ Dalla Lana School of Public Health (DLSPH), University of Toronto, Toronto, Canada. ${ }^{4}$ Addiction Info Suisse, Lausanne, Switzerland. ${ }^{5}$ Alcohol Treatment Centre, Lausanne University Hospital CHUV, Lausanne, Switzerland. ${ }^{6}$ University of the West of England, Bristol, UK. Institute for Clinical Psychology and Psychotherapy, Dresden University of Technology, Dresden, Germany. ${ }^{8}$ Department of Psychiatry, University of Toronto, Toronto, Canada. ${ }^{9}$ Institute of Medical Science, University of Toronto, Toronto, Canada.

\section{Authors' contributions}

TK, GG, and JR conceptualized the overall article. TK, GG, KDS, GG, and JR contributed to the methodology, identified sources for risk relations and exposure, and contributed to the writing. TK performed all statistical analyses. All authors have approved the final version.

\section{Competing interests}

The authors declare that they have no competing interests.

Received: 14 June 2011 Accepted: 10 April 2012

Published: 10 April 2012

\section{References}

1. Murray CJL, Lopez A: Global mortality, disability, and the contribution of risk factors: global burden of disease study. Lancet 1997, 349:1436-1442.

2. World Health Organization: International classification of diseases and related health problems, 10th revision (version for 2007) Geneva, Switzerland: World Health Organization; 2007.

3. Rehm J, Baliunas D, Borges GLG, Graham K, Irving HM, Kehoe T, et al: The relation between different dimensions of alcohol consumption and burden of disease - An overview. Addiction 2010, 105:817-843.

4. Eide $G$, Heuch I: Attributable fractions: fundamental concepts and their visualization. Stat Methods Med Res 2001, 10:159-193.

5. Rothman KJ, Greenland S, Lash TL: Modern Epidemiology. 3 edition. PA, USA: Lippincott Williams \& Wilkins; 2008

6. Walter SD: The estimation and interpretation of attributable risk in health research. Biometrics 1976, 32:829-849.

7. Walter SD: Prevention of multifactorial disease. Am J Epidemiol 1980, 112:409-416.
8. Rehm J, Room R, Graham K, Monteiro M, Gmel G, Sempos C: The relationship of average volume of alcohol consumption and patterns of drinking to burden of disease - An overview. Addiction 2003, 98:1209-1228.

9. Rehm J, Room R, Monteiro M, Gmel G, Graham K, Rehn N, et al: Alcohol as a risk factor for global burden of disease. Eur Addict Res 2003, 9:157-164.

10. Gutjahr E, Gmel G, Rehm J: The relation between average alcohol consumption and disease: an overview. Eur Addict Res 2001, 7:117-127.

11. Roerecke $M$, Rehm J: Irregular heavy drinking occasions and risk of ischemic heart disease: a systematic review and meta-analysis. Am J Epidemiol 2010, 171:633-644.

12. Puddey IB, Rakic V, Dimmitt SB, Beilin LJ: Influence of pattern of drinking on cardiovascular disease and cardiovascular risk factors - a review. Addiction 1999, 94:649-663.

13. Taylor B, Irving HM, Kanteres F, Room R, Borges G, Cherpitel C, et al: The more you drink, the harder you fall: a systematic review and metaanalysis of how acute alcohol consumption and injury or collision risk increase together. Drug Alcohol Depend 2010, 110:108-116.

14. Gmel G, Kuntsche E, Rehm J: Risky single occasion drinking: bingeing is not bingeing. Addiction 2011, 106:1037-1045.

15. Rehm J, Kehoe T, Gmel G, Stinson F, Grant B, Gmel G: Statistical modeling of volume of alcohol exposure for epidemiological studies of population health: the example of the US. Popul Health Metr 2010, 8:3.

16. Rehm J, Mathers C, Popova S, Thavorncharoensap M, Teerawattananon Y, Patra J: Global burden of disease and injury and economic cost attributable to alcohol use and alcohol use disorders. Lancet 2009, 373:2223-2233.

17. Patra J, Taylor B, Rehm J, Baliunas D, Popova S: Substance-attributable morbidity and mortality changes to Canada's epidemiological profile: measurable differences over a ten-year period. Can J Public Health 2007, 98:228-234.

18. Duffy JC: The distribution of alcohol consumption - 30 years on. $\mathrm{Br} J$ Addict 1986, 81:735-741.

19. Skog OJ: The distribution of alcohol consumption. Part I. A critical discussion of the Ledermann Model Oslo, Norway: National Institute for Alcohol Research; 1982.

20. Guttorp P, Hiang H: A note on the distribution of alcohol consumption. Drinking and Drug Practices Surveyor 1977, 13:7-8.

21. Skog OJ: A note on the distribution of alcohol consumption; Gamma vs Lognormal distributions. A reply to Guttorp and Song. Drinking and Drug Practices Surveyor 1979, 14:3-6.

22. Skog OJ: The tail of the alcohol consumption distribution. Addiction 1993, 88:601-610.

23. Gruenewald P, Nephew T: Drinking in California: Theoretical and empirical analyses of alcohol consumption patterns. Addiction 1994, 89:707-723.

24. Rehm J, Room R: Monitoring of alcohol use and attributable harm from an international perspective. Contemp Drug Probl 2009, 36:575-588.

25. World Health Organization: Global status report on alcohol and health Geneva, Switzerland, World Health Organization.

26. Rehm J, Klotsche J, Patra J: Comparative quantification of alcohol exposure as risk factor for global burden of disease. Int J Methods Psychiatr Res 2007, 16:66-76.

27. Rehm J, Room R, Monteiro M, Gmel G, Graham K, Rehn N, et al: Alcohol Use. In Comparative quantification of health risks: global and regional burden of disease attributable to selected major risk factors. Edited by: Ezzati M, Lopez AD, Rodgers A, Murray CJL. Geneva, Switzerland: World Health Organization; 2004:959-1109.

28. Midanik LT: The validity of self-reported alcohol consumption and alcohol problems: a literature review. Br J Addict 1982, 77:357-382.

29. Midanik L: Validity of self-reported alcohol use: a literature review and assessment. Br J Addict 1988, 83:1019-1029.

30. Shield K, Rehm J: Difficulties with telephone-based surveys on alcohol in high-income countries: the Canadian example. International Journal of Methods in Psychiatric Research 2009.

31. Gmel G, Rehm J: Measuring alcohol consumption. Contemp Drug Probl 2004, 31:467-540.

32. World Health Organization: Global strategy to reduce the harmful use of alcohol. Geneva, Switzerland: World Health Organization; 2010 [http://www. who.int/substance_abuse/activities/globalstrategy/en/index.html]. 
33. Bloomfield K, Allamani A, Back F, Bergmark KH, Csemy L, Eisenbach-Stang I, et al: Gender, culture and alcohol problems: a multi-national study. An EU concerted Action. Project final report. Berlin, Germany: Institut for Medical Informatics, Biometrics \& Epidemiology; 2005.

34. Bloomfield K, Gmel G, Wilsnack S: Introduction to special issue 'Gender, Culture and Alcohol Problems: a Multi-national Study'. Alcohol 2006, 41:3-7.

35. Taylor B, Rehm J, Trinidad J, Aburto C, Bejarano J, Cayetano C, et al: Alcohol, gender, culture and harms in the Americas: PAHO Multicentric Study final report Washington, D.C.: Pan American Health Organization (PAHO); 2007.

36. World Health Organization: WHO STEPS Surveillance Manual Geneva, Switzerland: World Health Organization; 2008.

37. Ledermann S: In Alcool, Alcoolisme, Alcoolisation. Volume Volume I. Paris, France: Presses Universitaires de France; 1956.

38. Ledermann S: In Alcool, Alcoolisme, Alcoolisation. Volume Volume II. Paris, France: Presses Universitaires de France; 1964.

39. Ypma TJ: Historical development of the Newton-Raphson method. Society for Industrial and Applied Mathematics 1995, 37:531-551.

40. Baliunas D, Taylor B, Irving H, Roerecke M, Patra J, Mohapatra S, et al: Alcohol as a risk factor for type 2 diabetes - A systematic review and meta-analysis. Diabetes Care 2009, 32:2123-2132.

41. Corrao G, Bagnardi V, Zambon A, La Vecchia C: A meta-analysis of alcohol consumption and the risk of 15 diseases. Prev Med 2004, 38:613-619.

42. Irving HM, Samokhvalov A, Rehm J: Alcohol as a risk factor for pancreatitis. A systematic review and meta-analysis. JOP 2009, 10:387-392.

43. R Development Core Team: R: A Language and Environment for Statistical Computing (version 2.13.0). Vienna, Austria: R Foundation for Statistical Computing; 2011.

44. Institute for Health Metrics and Evaluation: GBD operations manual final draft., [cited 2011]. Available from: URL: http://www.who.int/healthinfo/ global_burden_disease/GBD_2005_study/en/index.html.

doi:10.1186/1478-7954-10-6

Cite this article as: Kehoe et al:: Determining the best population-level alcohol consumption model and its impact on estimates of alcoholattributable harms. Population Health Metrics 2012 10:6.

\section{Submit your next manuscript to BioMed Central} and take full advantage of:

- Convenient online submission

- Thorough peer review

- No space constraints or color figure charges

- Immediate publication on acceptance

- Inclusion in PubMed, CAS, Scopus and Google Scholar

- Research which is freely available for redistribution

Submit your manuscript at www.biomedcentral.com/submit
CioMed Central 